\title{
Neutron capture in low mass Asymptotic Giant Branch stars: cross sections and abundance signatures
}

\author{
Claudio Arlandini ${ }^{1}$, Franz Käppeler ${ }^{2}$ and Klaus Wisshak ${ }^{3}$ \\ Forschungszentrum Karlsruhe, Institut für Kernphysik, Postfach 3640, D-76021 Karlsruhe, \\ Germany \\ Roberto Gallino ${ }^{4}$ \\ Dipartimento di Fisica Generale, Università di Torino, I-10125 Torino, Italy \\ Maria Lugaro 5 \\ Department of Mathematics, Monash University, Clayton, Victoria 3168, Australia \\ Maurizio Busso ${ }^{6}$ \\ Osservatorio Astronomico di Torino, I-10025 Torino, Italy \\ and \\ Oscar Straniero ${ }^{7}$ \\ Osservatorio Astronomico di Collurania, I-64100 Teramo, Italy
}

Received __; accepted _

\footnotetext{
${ }^{1}$ email: claudio@ik3.fzk.de

${ }^{2}$ email: kaepp@ik3.fzk.de

${ }^{3}$ email: wisshak@ik3.fzk.de

${ }^{4}$ email: gallino@ph.unito.it

${ }^{5}$ email: marial@thala.maths.monash.edu.au

${ }^{6}$ email: maurizio@otoxd6.to.astro.it

${ }^{7}$ email: straniero@astrte.te.astro.it
} 


\begin{abstract}
The recently improved information on the stellar $(n, \gamma)$ cross sections of neutron-magic nuclei at $N=82$, and in particular of ${ }^{142} \mathrm{Nd}$, turned out to represent a sensitive test for models of $s$-process nucleosynthesis. While these data were found to be incompatible with the classical approach based on an exponential distribution of neutron exposures, they provide significantly better agreement between the solar abundance distribution of $s$ nuclei and the predictions of models for low mass AGB stars. The origin of this phenomenon is identified as being due to the high neutron exposures at low neutron density obtained between thermal pulses when the ${ }^{13} \mathrm{C}$ burns radiatively in a narrow layer of a few $10^{-4} M_{\odot}$. This effect is studied in some detail, and the influence of the presently available nuclear physics data is discussed with respect to specific further requests. In this context, particular attention is paid to a consistent description of $s$-process branchings in the region of the rare earth elements. It is shown that - in certain cases - the nuclear data are sufficiently accurate that the resulting abundance uncertainties can be completely attributed to stellar modelling. Thus, the $s$ process becomes important for testing the role of different stellar masses and metallicities as well as for constraining the assumptions for describing the low neutron density provided by the ${ }^{13} \mathrm{C}$ source.
\end{abstract}

Subject headings: stars: AGB - stars: evolution - stars: low mass nucleosynthesis 


\section{Introduction}

In the last thirty years studies of the slow neutron capture process ( $s$ process) have been pursued either through nucleosynthesis computations in stellar models for the Thermally Pulsing Asymptotic Giant Branch (TP-AGB) phases of low and intermediate mass stars (Ulrich 1973; Truran \& Iben 1977; Hollowell \& Iben 1988; Käppeler et al. 1990; Straniero et al. 1995; Gallino et al. 1998) or by phenomenological models, mostly by the so-called classical approach, which were developed with the heuristic intention to provide a possibility for a "model-free" description. In this last case, simple analytical expressions are used for the neutron irradiation and, to first approximation, any time dependence of the physical parameters is neglected (see e.g. Käppeler, Beer, \& Wisshak 1989). For a brief historical account of s-process analyses see Gallino, Busso, \& Lugaro (1997).

For low mass stars, the two descriptions appeared to be compatible within the respective uncertainties, in particular after the ${ }^{13} \mathrm{C}(\alpha, n){ }^{16} \mathrm{O}$ neutron source was recognized to play a major role on the AGB (Gallino et al. 1988; Hollowell \& Iben 1988). There, the $s$ process was assumed to occur in convective thermal pulses, the classical analysis was considered to yield "effective" conditions characterizing the stellar scenarios (Käppeler et al. 1990).

This situation changed after it was realized that ${ }^{13} \mathrm{C}$ burns radiatively in the time interval between two successive convective He-shell instabilities (Straniero et al. 1995). The interplay of the different thermal conditions for the ${ }^{13} \mathrm{C}$ and ${ }^{22} \mathrm{Ne}$ neutron sources, both contributing to the nucleosynthesis process, is hardly represented by a single set of effective parameters like those commonly used by the classical approach. This is particularly true for the description of the neutron exposure, which is usually simplified by an exponential distribution. In contrast, present stellar models show that the distribution of neutron exposures is definitely non-exponential, and actually very difficult to be 
described analytically (Arlandini et al. 1995). Any attempt to describe this picture in a phenomenological way would require to increase the number of free parameters, in contradiction to the basic reason for such an approach as a model-independent guideline for stellar calculations.

Despite of the substantial differences between classical approach and the complex AGB models, the classical analysis is, however, still reproducing the $s$ abundances for the majority of nuclei between $\mathrm{Sr}$ and $\mathrm{Bi}$, simply because two conditions are commonly satisfied in the mass regions between magic neutron numbers: the respective neutron capture rates are independent of temperature due to the $1 / v$-behavior of the $(n, \gamma)$ cross sections and are sufficiently large to establish steady flow equilibrium. Consequently, the resulting $s$ abundances are to good approximation inversely proportional to the Maxwellian averaged cross sections.

Nevertheless, the differences between classical approach and detailed AGB models become the more evident the more accurate $(n, \gamma)$ rates of nuclei involved in $s$-process branchings and/or with strong deviations from a $1 / v$-behavior are becoming available. A region of the $s$-process path where this is particularly evident is that involving the neutron-magic nuclei at $N=82$, including the $s$-only isotope ${ }^{142} \mathrm{Nd}$. Recent accurate measurements of the stellar neutron capture cross sections for all stable isotopes in this area (Wisshak et al. 1998a, 1998b; Voss et al. 1999) revealed a number of significant discrepancies compared to the older data (see compilations by Bao \& Käppeler 1987; Beer, Voss, \& Winters 1992), resulting in a situation where the classical approach implies a large overproduction of ${ }^{142} \mathrm{Nd}$ for any reasonable parameter set. This problem was already noted by Guber et al. (1997), but their relatively large cross section uncertainty did not allow any firm conclusions. At the same time the new data were found to be fully compatible with the results of the stellar model. 
The consequences of this discrepancy will be the subject of the present paper. We show how the classical model leads to internal inconsistencies, at least near neutron-magic nuclei, which seem to be the inescapable consequence of this simplifying approach. On the other hand, stellar models appear increasingly successful in describing the many facets of the $s$-abundance patterns, regardless of their much higher complexity. An important aspect in this discussion will be that average quantities, such as the effective values for the neutron density and temperature deduced in the classical approach, do not easily relate to the true features of the stellar scenario. That holds even for the zones of the $s$-process path where both models provide a satisfactory reproduction of the solar $s$ abundances. Also more complex phenomenological models with an increasing number of free parameters lack a detailed comprehension of the physical conditions at the $s$-process site.

Finally, we note that the use of the solar $s$ abundances as a constraint for $s$-process studies has to be made with caution, since the $s$ process is not a unique event but rather the result of a complex Galactic evolution mechanism. In particular, the $s$-process distribution varies strongly for TP-AGB stars with different metallicity (Busso, Gallino, \& Wasserburg 1999; Travaglio et al 1999; Raiteri et al. 1999). Therefore, the comparison with the solar distribution has to be complemented by direct observations in different types of $s$-enriched stars as well by the signatures carried by interstellar grains.

In $\S 2$ an overview of the $s$-process models is presented. In $\S 3$ and $\S 4$ we discuss the effect of the new nuclear physics input data on the classical approach and stellar model calculations, respectively. In $\S 5$ the relevance of the uncertainties of some aspects of the stellar evolution calculations on the $s$-process nucleosynthesis results are discussed. This is followed in $\S 6$ by an analysis of some relevant branchings of the $s$-process reaction path. In $\S 7$, we conclude with a presentation of the $r$-process residuals obtained with the two approaches and some final remarks in $\S 8$. 


\section{The $s$-process models}

Since the early works (Seeger, Fowler, \& Clayton 1965; Clayton \& Rassbach 1967; Clayton \& Ward 1974), the process of slow neutron addition in red giants has been approximated by a phenomenological approach, consisting of an analytical formulation for the distribution of $\langle\sigma\rangle^{i} N_{s}^{i}$ products, where $N_{s}^{i}$ is the fractional $s$ abundance of nucleus $i$ and $\langle\sigma\rangle^{i}=\langle\sigma v\rangle^{i} / v_{T}$ is its Maxwellian averaged neutron capture cross section, with $v_{T}$ thermal velocity. It is known (Clayton 1968) that such a formulation is obtained by adopting a suitable distribution of neutron exposures $\rho(\tau)$, where $\tau$ means the time-integrated neutron flux.

Over the years, this procedure has been particularly successful for the so-called main $s$-process component, accounting for $s$-nuclei between magic neutron numbers $N=50$ and 126, i.e. for mass numbers $88<A<208$. Traditionally, the most common form for $\rho(\tau)$ was an exponential distribution,

$$
\rho(\tau)=\frac{G N_{\odot}^{56}}{\tau_{0}} \exp \left(-\tau / \tau_{0}\right),
$$

that proved very effective in reproducing the solar system $\langle\sigma\rangle N_{s}$ curve with the fit of only two parameters: the fraction $G$ of the solar iron abundance that would be required as a seed, and the mean neutron exposure $\tau_{0}$. The treatment of branchings, as formulated by Ward, Newman, \& Clayton (1976), requires three additional parameters, namely the temperature, $T$, the neutron density, $n_{n}$, and the electron density, $n_{e}$.

A physical justification for the choice of $\rho(\tau)$ seemed to appear when Ulrich (1973) showed that an exponential distribution of exposures was the natural consequence of repeated He-shell flashes during the AGB phase. The exponential distribution was shown to derive simply from the partial overlap of subsequent thermal pulses. With a constant exposure $\Delta \tau$ per pulse, and a constant overlap factor $r$, after $N$ pulses the fraction of 
material having experienced an exposure $\tau=N \Delta \tau$ is $\sim r^{N} \equiv \exp \left(-\tau / \tau_{0}\right)$, where the the mean exposure $\tau_{0}$ is defined as $\tau_{0}=-\Delta \tau / \ln r$.

The pulsed nature of the neutron source was later recognized by the analysis of the branching at ${ }^{85} \mathrm{Kr}$ (Ward \& Newman 1978), and taken into account in more complex phenomenological approaches (Beer 1991). The classical analysis was found to be a useful way of describing the $s$ abundances, as it provided an apparently consistent, simple and straightforward description of the $s$ process, suggesting it to occur in a stellar environment with physical parameters corresponding to those inferred from this model.

Meanwhile, the knowledge of the last stages of evolution for AGB stars was improved by a series of investigations originally based on the activation of the ${ }^{22} \mathrm{Ne}(\alpha, n)^{25} \mathrm{Mg}$ reaction in intermediate mass stars (IMS) (e.g. Truran \& Iben 1977; Cowan et al. 1980; Busso et al. 1988), and subsequently emphasizing the importance of the alternative ${ }^{13} \mathrm{C}(\alpha$, $n)^{16} \mathrm{O}$ reaction in low mass stars (LMS) Gallino et al. 1988; Hollowell \& Iben 1988; Käppeler et al. 1990). The latter models finally suggested that the main $s$-process component results from the interplay of both neutron sources in LMS with masses between 1.5 and $3 M_{\odot}$. The present status of this field of research was recently updated on the basis of revised stellar models, including a self-consistent mixing mechanism for the transport of freshly synthesized material from the He shell to the stellar surface, the so-called third dredge-up (TDU) (Straniero et al. 1997). Accordingly, the abundance distributions considered in the following refer to the composition of the TDU material integrated over the whole AGB phase and lost by stellar winds. This composition represents the $s$-process enrichment of the interstellar medium by the considered model star. This has to be considered in comparisons with the $s$-process enhancements observed in chemically peculiar red giants (Smith \& Lambert 1985, 1986,1990; Lambert et al. 1995; Busso et al. $1992,1995,1999)$. 
According to the above LMS models, the ${ }^{13} \mathrm{C}$ neutron source is activated under radiative conditions during the intervals between subsequent He-shell burning episodes. While the ${ }^{13} \mathrm{C}$ reaction provides the bulk of the neutron exposure already at low temperatures $(k T$ $\simeq 8 \mathrm{keV})$ and neutron densities $\left(n_{n} \leq 10^{7} \mathrm{~cm}^{-3}\right)$, the produced abundances are modified by the marginal activation of the ${ }^{22} \mathrm{Ne}$ source during the next convective instability, when high peak neutron densities of $n_{n} \leq 10^{10} \mathrm{~cm}^{-3}$ are achieved at $k T \simeq 23 \mathrm{keV}$. Though this second neutron burst represents only a few percent of the total exposure, it suffices to modify the abundance patterns of several temperature- and neutron-density-dependent branchings. The time dependence of this second burst is particularly important for defining the freeze-out conditions for most of these branchings.

Remarkably similar physical conditions are found in AGB models down to a metallicity slightly lower than $1 / 2$ solar $(-0.4 \leq[\mathrm{Fe} / \mathrm{H}] \leq 0)$ by Gallino et al. (1998). Though observations in MS and S stars in the solar neighborhood (Smith \& Lambert 1990; Busso et al. 1992) exhibit a spread in the respective $s$ abundances, most Galactic disk AGB stars in the mass range $1.5 \leq M / M_{\odot} \leq 3$ can be considered as suitable sites for reproducing the main component: while the solar $s$ composition is clearly the product of an average over Galactic astration processes from various generations of AGB stars with different $s$-process efficiencies, according to the initial mass, metallicity, and mass loss mechanism, it is remarkable that the solar $s$-abundance distribution lays roughly at the center of the spread observed in MS and S stars (Busso et al. 1999). The actual neutron capture nucleosynthesis efficiency in each star depends on the metallicity, the choice of the amount of ${ }^{13} \mathrm{C}$ that is burnt, and its profile in the intershell region, i.e. on what has become known as the ${ }^{13} C$ pocket. In order to model this essential feature, which is controlled by partial proton mixing below the formal convective envelope border, a detailed hydrodynamical treatment of the $\mathrm{H} / \mathrm{He}$ interface is required. Presently available hydrostatic stellar models cannot account for this phenomenon. Thus, in our computations it is still parameterized in a relatively free 
way (see e.g. Gallino et al. 1998; Busso, Gallino, \& Wasserburg 1999 for a discussion). Hence, the AGB nucleosynthesis results presented here, which are shown to account for the main $s$-process component, are based on suitable choices for the ${ }^{13} \mathrm{C}$ pocket and metallicity. They should be considered as the nucleosynthesis pattern of a particular AGB star of the Galactic disk, whose $s$-process abundance distribution closely matches the main $s$-process component. As said, it is a relatively common occurrence in the Galaxy.

\section{The ${ }^{142} \mathrm{Nd}$ cross section and the limits of the classical approach}

\subsection{New cross sections}

The $s$-process abundance of ${ }^{142} \mathrm{Nd}$, shielded against a $r$-process contribution by ${ }^{142} \mathrm{Ce}$ (Fig. 1), is influenced by two small branchings in the neutron capture path at ${ }^{141} \mathrm{Ce}$ and ${ }^{142} \mathrm{Pr}$. Provided the $p$-process contribution be negligible, the branching probabilities follow from the comparison of the empirical product $\langle\sigma\rangle N_{s}$ of the stellar neutron capture cross section and the solar ${ }^{142} \mathrm{Nd}$ abundance with the $\langle\sigma\rangle N_{s}$ systematics in the local mass region. The expected branching factor is about 5\%, so a meaningful analysis was hampered by the uncertainties in the nuclear physics data, especially by the $9 \%$ uncertainty of the ${ }^{142} \mathrm{Nd}$ cross section (Beer et al. 1992). Recently, experimental determinations of the stellar neutron capture cross sections of ${ }^{140,142} \mathrm{Ce}$ (Käppeler et al. 1996), ${ }^{141} \operatorname{Pr}$ (Voss et al. 1999) and of all the stable Nd isotopes (Wisshak et al. 1998a, 1998b; Toukan et al. 1995) have been provided with uncertainties of $1-2 \%$ along with new cross section calculations for the unstable branch point nuclei ${ }^{141} \mathrm{Ce}$ and ${ }^{142} \operatorname{Pr}$ (Käppeler et al. 1996). The significant discrepancies with respect to previous data (see Table 1) triggered a detailed $s$-process analysis.

EDITOR: PLACE TABLE — HERE. 


\section{EDITOR: PLACE FIGURE 1 HERE.}

The stellar neutron capture cross sections of ${ }^{142,144} \mathrm{Nd}$ were also recently measured by Guber et al. (1997). While the values agree within the quoted uncertainties at $30 \mathrm{keV}$, a serious discrepancy is found for ${ }^{144} \mathrm{Nd}$ at $k T \leq 20 \mathrm{keV}$. However, this discrepancy had no effect in the present study. The adopted Ce, Pr, and Nd cross sections were obtained at the Karlsruhe 3.75 MV Van de Graaff accelerator. The cerium cross sections were measured with an activation method, while the neodymium and praseodymium experiments were performed with the Karlsruhe $4 \pi$ Barium Fluoride $\left(\mathrm{BaF}_{2}\right)$ detector and the time-of-flight (TOF) method.

The activation method consists in irradiating a sample in a quasistellar neutron spectrum, obtained by bombarding a thick metallic Li target with protons of $1912 \mathrm{keV}$, just above the reaction threshold. The ${ }^{7} \operatorname{Li}(p, n)^{7}$ Be reaction then yields a continuous energy distribution with a high energy cutoff at $E_{n}=106 \mathrm{keV}$. The resulting neutrons are emitted in a forward cone of $120^{\circ}$ opening angle. The angle integrated spectrum closely resembles a Maxwellian distribution peaked at $25 \mathrm{keV}$, thus exhibiting almost exactly the shape required to determine directly the stellar cross section. The samples are placed on the lithium target, sandwiched between gold foils. The simultaneous activation of the gold foils serves for normalization, since both the stellar neutron capture cross section of ${ }^{197} \mathrm{Au}(n$, $\gamma)^{198} \mathrm{Au}$ (Ratynski \& Käppeler 1988) and the decay parameters of ${ }^{198} \mathrm{Au}$ (Auble 1983) are accurately known. A more detailed description of the method and of the experimental setup can be found in Beer \& Käppeler (1980). After activation, the $\gamma$-rays from the decay of the product nuclei are counted with a high-purity Ge-detector.

As for the TOF experiments, the neutron energies were determined by time of flight, with the samples being located at a flight path of $79 \mathrm{~cm}$. Adjusting the proton energy slightly above the reaction threshold a continuous neutron spectrum in the energy range 
relevant for the determination of the Maxwellian averaged stellar cross sections, i.e. from 3 to $200 \mathrm{keV}$, is obtained. Capture events were registered with the Karlsruhe $4 \pi$ Barium Fluoride detector via the prompt capture $\gamma$-ray cascades. This detector consists of 42 hexagonal and pentagonal crystals forming a spherical shell with $10 \mathrm{~cm}$ inner radius and 15 $\mathrm{cm}$ thickness. It is characterized by a resolution in $\gamma$-ray energy of $7 \%$ at $2.5 \mathrm{MeV}$, a time resolution of $500 \mathrm{ps}$, and a peak efficiency of $9 \%$ at $1 \mathrm{MeV}$. A comprehensive description can be found in Wisshak et al. (1990). Again, the stellar cross sections are calculated using gold as a standard.

The TOF method represents a universal approach, the only limitation being a minimum sample mass. On the other hand, the activation technique offers a far superior sensitivity, since the samples can be placed directly at the neutron production target in a much higher neutron flux. However, this method can only be applied to cases where the product nucleus is unstable. Also, the systematic uncertainties are somewhat larger than those typical for the TOF method.

The cross sections being determined with uncertainties at the 1-2\% level, the $s$-process abundances are derived with similar accuracy. Therefore, possible $p$-process contributions can no longer be neglected. This correction is most important for the $s$ - only nuclei, which are shielded only against the $r$-process $\beta$-decays. An empirical determination based on the abundances of local $p$ - only isotopes would suggest a contribution of $\sim 9 \%$ for ${ }^{142} \mathrm{Nd}$, but available $p$-process calculations (Rayet, Prantzos, \& Arnould 1990; Prantzos et al. 1990; Howard, Meyer, \& Woosley 1991; Rayet 1991; Howard 1991; Rayet et al. 1995) give lower values of $\sim 4 \%$. Such comparably large $p$-process abundance is plausible, since ${ }^{142} \mathrm{Nd}$ is the heaviest neutron-magic stable nucleus with $N=82$ and is, therefore, favored in a $p$-process environment, where the $(\gamma, n)$ flow is damped at the higher neutron binding energies. Additionally, ${ }^{142} \mathrm{Nd}$ is enhanced by the decay of its $\alpha$-unstable $p$-process progenitors ${ }^{146} \mathrm{Sm}$, 
${ }^{150} \mathrm{Gd}$, and ${ }^{154} \mathrm{Dy}$. Another small correction refers to the effect of thermally populated excited nuclear states. However, such possible enhancements of the $(n, \gamma)$ cross sections do not influence the rates used in this discussion.

\subsection{The classical approach}

${ }^{142} \mathrm{Nd}$ is located immediately at the pronounced precipice of the $\langle\sigma\rangle N_{s}$ curve that is caused by the small $(n, \gamma)$ cross sections at $N=82$. Hence, its cross section determines not only the branching analysis, but also the general shape of the $s$-process distribution, which is described in the classical approach via the mean exposure, $\tau_{0}$. Since the $\beta$-decay rates of ${ }^{141} \mathrm{Ce}$ and ${ }^{142} \mathrm{Pr}$ are almost independent of the stellar temperature Takahashi \& Yokoi 1987), these branchings will be completely defined by the effective $s$-process neutron density. This parameter can best be determined by means of the $s$-only pair ${ }^{148} \mathrm{Sm}$ and ${ }^{150} \mathrm{Sm}$. As the result of three branchings at ${ }^{147} \mathrm{Nd}$, and ${ }^{147,148} \mathrm{Pm}$, the first isotope, ${ }^{148} \mathrm{Sm}$, is partially bypassed while ${ }^{150} \mathrm{Sm}$ experiences the entire $s$-process flow. The effective neutron density is found to be $n_{n}=(4.1 \pm 0.6) \times 10^{8} \mathrm{~cm}^{-3}$ (Toukan et al. 1995). A more accurate determination requires an experimental value for the stellar neutron capture cross section of ${ }^{147} \mathrm{Pm}$.

Following the concept of Ulrich (1973), classical $s$-process calculations have been performed by means of the network code NETZ (Jaag 1990), using a neutron density of $4.1 \times 10^{8} \mathrm{~cm}^{-3}$. The adopted thermal energy was $k T=30 \mathrm{keV}$, according to the analysis of Wisshak et al. (1995) on the branchings bypassing the $s$-only isotopes ${ }^{152,154} \mathrm{Gd}$, which constrained the $s$-process temperature to $28 \leq k T \leq 33 \mathrm{keV}$. The electron density $n_{e}$ $=5.4 \times 10^{26} \mathrm{~cm}^{-3}$ was obtained from a reanalysis of the branching at $A=163$ feeding ${ }^{164} \operatorname{Er}$ (Best 1996; Arlandini, Käppeler, \& Wisshak 1998). The best fit of the solar system distribution for the $s$-nuclei belonging to the main component is obtained for 
$\tau_{0}=(0.296 \pm 0.003)[k T / 30]^{1 / 2} \mathrm{mbarn}^{-1}$, slightly lower than the previously adopted value of $(0.300 \pm 0.009)[k T / 30]^{1 / 2} \operatorname{mbarn}^{-1}$ (Käppeler et al. 1990, correctly extrapolating the value given at $k T=29 \mathrm{keV})$. Note the significant reduction in the uncertainty of $\tau_{0}$, which is due the improved cross sections around $N=82$. The quality of the fit is evaluated by using the unbranched $s$-only nuclei as normalization points, i.e. ${ }^{100} \mathrm{Ru},{ }^{110} \mathrm{Cd},{ }^{116} \mathrm{Sn},{ }^{122,123,124} \mathrm{Te}$, ${ }^{150} \mathrm{Sm}$, and ${ }^{160} \mathrm{Dy}$. The root mean square deviation of their calculated $\langle\sigma\rangle N_{s}$ values from the respective empirical points is

$$
\delta=\left[\frac{1}{n} \sum \frac{\left(\langle\sigma\rangle N^{\text {calc }}-\langle\sigma\rangle N^{e m p}\right)^{2}}{\left(\langle\sigma\rangle N^{e m p}\right)^{2}}\right]^{1 / 2}=6 \% .
$$

This mean deviation is larger than reported previously (Käppeler et al. 1990), since it includes ${ }^{160} \mathrm{Dy}$, whose cross section has been experimentally determined and may well be influenced by the stellar temperature (Voss et al. 1999). Without ${ }^{160}$ Dy, this value would reduce to $4 \%$.

\section{EDITOR: PLACE FIGURE 2 HERE.}

Fig. 2 (bottom left panel) shows that the ${ }^{142} \mathrm{Nd}$ is overproduced by $\sim 12 \%$, despite the fact that it is partly bypassed by the reaction flow. This overproduction is neither compatible with the $2 \%$ cross section uncertainty at $30 \mathrm{keV}$, nor with the uncertainty of the solar abundance, because the abundance ratio between the chemically related rare earth elements Nd and Sm is known to the 1.8\% level (Anders \& Grevesse 1989). Furthermore, the overproduction factor has to be considered as a lower limit, due to the non-negligible $p$-process contribution. Accordingly, ${ }^{142} \mathrm{Nd}$ is the first clear evidence that the simple assumptions of the classical model are not adequate to describe the $s$ process.

Previously, similar difficulties of the classical model were noted already in connection with the notorious underproduction of ${ }^{116} \mathrm{Sn}$ and the overproduction of the $s$-only isotope 
${ }^{136} \mathrm{Ba}$ (Voss et al. 1994; Wisshak et al. 1996), but in these cases the solar Sn and Ba abundances were too uncertain to allow for a conclusive argument. Another problem of the classical approach was related to the overproduction of ${ }^{86} \mathrm{Kr}$ and ${ }^{87} \mathrm{Rb}$ (see e.g. Käppeler et al. 1990) due to the branching at ${ }^{85} \mathrm{Kr}$. Even if the contribution from the $r$ process and from the weak component are neglected, the classical approach yields large overabundances with respect to the other $s$ nuclei. A possible solution was suggested by the assumption of a pulsed $s$ process in more complex phenomenological approaches (Ward \& Newman 1978; Beer \& Macklin 1989; Beer 1991), constraining the neutron pulse duration to 3 yr $\leq \Delta t \leq$ $20 \mathrm{yr}$.

\subsection{Other phenomenological models}

In order to understand if the failure of the classical model may be considered in a more general way, we analyzed also other parametrized approaches. Seeger, Fowler, \& Clayton (1965), following a suggestion by Clayton et al. (1961), found that the solar $s$-distribution can be adequately fitted by a discrete superposition of a limited number (four in their example) of single neutron exposures. We computed a grid of 50 distributions for single neutron exposures with $\Delta \tau$ ranging from 0.03 to $3.50 \mathrm{mbarn}^{-1}$, assuming a constant neutron density of $4.1 \times 10^{8} \mathrm{~cm}^{-3}$ and varying the irradiation time. The solar distribution of all $s$-only isotopes was fitted from $\mathrm{Fe}$ to $\mathrm{Pb}$ as a weighted sum of four exposures, using a $\chi^{2}$ method. The most promising results fall in two groups, the first consisting of solutions that are very similar to those obtained with an exponential exposure distribution for the main component. These cases provide a good overall reproduction of the solar abundances, but

yield strong overproductions of ${ }^{142} \mathrm{Nd}$ and ${ }^{136} \mathrm{Ba}$. They include also a very small exposure, which mimics the so-called weak component, representing the $s$ process in massive stars. This component accounts for most of the $s$ abundances below $A=90$. The second group 
allowed for an excellent reproduction of all s-only isotopes from Te to Sm, but led to unavoidable and unacceptable overproductions of more than $10 \%$ for all isotopes lighter than Te or heavier than Sm, including the important normalization points ${ }^{100} \mathrm{Ru}$ and ${ }^{110} \mathrm{Cd}$. Therefore, this idea of a superposition of a limited number of single neutron exposures was found to be no more successful than the classical approach.

A model describing the pulsed burning of two neutron sources with an exponential distribution of exposures was suggested by Beer (1991) and Beer et al. (1997). Although the number of free parameters is more than doubled with respect to the classical model, the fit to the solar main $s$ component is only slightly better, since it does not solve the Sn and Ba problems, nor is it able to provide consistent constraints on the astrophysical conditions of the $s$ process.

The same problems are not solved by the model proposed by Goriely (1997), which fits the solar distribution with a large grid of components, each characterized by a given neutron irradiation and different constant temperatures and neutron densities. Using an iterative inversion procedure and without setting any predefined limit to the parameter space, the solution shows a distribution of exposures that is very close to an exponential law.

\section{The new ${ }^{142} \mathrm{Nd}$ cross section: Success for the AGB model}

A thorough description of the model and the adopted reaction network can be found in Gallino et al. (1998). The neutron capture calculations start from evolutionary computations for low mass stars up to end of the AGB phase, which were made with the latest version of the FRANEC code (Chieffi \& Straniero 1989; Straniero et al. 1997; Chieffi, Limongi, \& Straniero 1998) for a range of initial masses, $1.5 \leq M_{\odot} \leq 3$, and metallicities,

$-0.4 \leq[\mathrm{Fe} / \mathrm{H}] \leq 0$. In addition, the influence of various mass-loss rates was checked as well. 
No TDU was found for lower masses. A satisfactory reproduction of the solar distribution of $s$ isotopes in the range $88<A<208$ can be obtained for all these stars, since their physical conditions are quite similar. In this way, the only free parameters of the neutron capture model, which are the total amount of ${ }^{13} \mathrm{C}$ burnt and its profile in the pocket, could be constrained. As a general rule it was found that very similar $s$-process abundance distributions can be obtained by contemporarily decreasing the metallicity and increasing the amount of ${ }^{13} \mathrm{C}$ in the pocket by the same factor. The object of this paper is to focus on the nuclei involved in branchings along the $s$ path, and in particular on the effect of the ${ }^{142} \mathrm{Nd}$ cross section.

\section{EDITOR: PLACE FIGURE 3 HERE.}

Following Gallino et al. (1998), we consider the best representation of the main component obtained for a star of $2 M_{\odot}, Z=1 / 2 Z_{\odot}$, and a Reimers mass loss rate with $\eta$ $=0.75$, as a standard case. The general improvement with respect to the classical solution (Fig. 3) is striking, especially since no fitting procedure was applied. ${ }^{134,136} \mathrm{Ba}$ are now overproduced by a mere 5\%, well compatible with the uncertainties of the neutron capture cross sections and solar abundances, not requiring any more the large corrections (20\%) to the solar barium advocated by the classical analysis (Voss et al. 1994). Also ${ }^{116} \mathrm{Sn}$, for which the classical analysis of Wisshak et al. (1996) suggested a $15 \%$ variation to the solar tin abundance, is now reproduced within the respective uncertainties. In this context, it is important to note that the meteoritic abundances of Ba and Sn quoted by Anders \& Grevesse (1989) were confirmed by an independent measurement (De Laeter, Rosman, \& Ly 1998). A similar measurement of the Te abundance, which is yet uncertain by $10 \%$ would be important as well.

As already shown by Straniero et al. (1995), the most relevant difference compared to the classical analysis is actually found in the mass region $A<88$. Indeed, all these 
nuclei (that are predominantly due to the weak $s$-component) are produced in much smaller quantities, even with respect to superseded stellar models, which assumed the convective burning of ${ }^{13} \mathrm{C}$. This difference is caused by the very high neutron exposures reached in the tiny pocket, which favor the production of heavier elements. In particular, at the $s$-termination path, ${ }^{208} \mathrm{~Pb}$ is produced four times more than in the classical approach.

This has obvious consequences for the branching at ${ }^{85} \mathrm{Kr}$. The low neutron density of the ${ }^{13} \mathrm{C}$ neutron release implies that the reaction flow to the neutron-rich nuclei ${ }^{86} \mathrm{Kr}$ and ${ }^{87} \mathrm{Rb}$ is weak, thus avoiding the overproduction of these isotopes that is a severe problem in the phenomenological approaches and in the old stellar models (Käppeler et al. 1990). In the present case the contribution from the weaker exposure due to the ${ }^{22} \mathrm{Ne}$ neutron source is small, because of the small cross section of ${ }^{85} \mathrm{Kr}$.

The ${ }^{85} \mathrm{Kr}$ branching regulates also the $\mathrm{Rb} / \mathrm{Sr}$ ratio, which has been measured in AGB stars showing $s$-process and carbon enrichments. With the definition $[X] \equiv \log _{10}\left(X_{\text {star }}\right)$ $\log _{10}\left(X_{\odot}\right)$, the average abundance ratio was found to be $[\mathrm{Rb} / \mathrm{Sr}]=-0.80 \pm 0.15$ (Lambert et al. 1995, Lambert 1995). Again, the new stellar model calculations are in good agreement with this stringent constraint.

As for the other significant differences compared to the classical approach, the analysis of the branchings to ${ }^{170} \mathrm{Yb}$ and ${ }^{192} \mathrm{Pt}$ is hampered by the poor knowledge of the relevant stellar $(n, \gamma)$ cross sections, while the branchings to ${ }^{180} \mathrm{Ta}$ (Schumann et al. 1998) and ${ }^{176} \mathrm{Lu}$ (Doll et al. 1999) remain uncertain because of the complex effect of the stellar temperature on the population of the respective ground and isomeric states.

In the region around $A \sim 140$, two aspects are immediately evident from Fig. 2. First, the new cross sections improve the situation in the stellar model, from a 30\% underproduction of ${ }^{142} \mathrm{Nd}$ to $4 \%$, well compatible with the predicted $p$-process abundance. On the other hand, the classical approach is facing the inherent overproduction of ${ }^{142} \mathrm{Nd}$ 
discussed in $§ 3.2$. The reason for reproducing ${ }^{142} \mathrm{Nd}$ correctly lies in the fact that the cross section deviates significantly from a 1/v-behavior. Accordingly, the ${ }^{13} \mathrm{C}$ source produces $8 \%$ less ${ }^{142} \mathrm{Nd}$ than the classical approach, which operates at $k T=30 \mathrm{keV}$. In the subsequent burst from the ${ }^{22} \mathrm{Ne}$ source relatively high peak neutron densities are reached for about one year, followed by a rapid freeze-out (Fig. 4, top panel). Due to its rather small cross section, the abundance of ${ }^{142} \mathrm{Nd}$ itself is depleted by no more than $10 \%$ during this phase, the initial level being rapidly restored during the decline of the neutron density.

\section{EDITOR: PLACE FIGURE 1 HERE.}

Secondly, the revised ${ }^{142} \mathrm{Nd}$ and ${ }^{144} \mathrm{Nd}$ cross sections affect the distribution of $s$ abundances up to $A \sim 160$ by a "propagation effect". Indeed, during the ${ }^{13} \mathrm{C}$ phase the neutron exposure is large enough to establish reaction equilibrium, producing an abundance reservoir at the neutron-magic nuclei. While this equilibrium is practically maintained during the peak neutron density of the subsequent ${ }^{22} \mathrm{Ne}$ burst, the decline of the neutron density leads to pronounced freeze-out effects near neutron-magic nuclei. Evidently, the abundances of the nuclei with the smallest cross sections freeze-out at first, whereas the isotopes beyond ${ }^{144} \mathrm{Nd}$ are depleted by further neutron captures. This effect causes an additional abundance difference between ${ }^{142} \mathrm{Nd}$ and ${ }^{150} \mathrm{Sm}$.

A further increase of this abundance difference results from the fact that the He shell is enriched in $s$-process material during the AGB phase due to the overlap of subsequent He-shell flashes.

The combination of all three effects accounts for the $12 \%$ discrepancy in the ${ }^{142} \mathrm{Nd}$ abundance between the classical approach and the stellar solution.

\section{STELLAR EVOLUTION ASPECTS}




\subsection{Parameters of the stellar models}

The presented results are affected by two kinds of uncertainties, those connected with the neutron capture process itself and those related to the stellar evolutionary calculations.

With respect to the parameters of the stellar model, it was already emphasized that the amount of primary ${ }^{13} \mathrm{C}$ and its profile in the pocket cannot be obtained through canonical evolutionary models and have to be, therefore, parameterized. The reasons for the choice of the adopted profile are described by Gallino et al. (1998).

With the evolution of temperature and density in the ${ }^{13} \mathrm{C}$ pocket provided by the evolutionary models, the neutron release is determined by the rate of the ${ }^{13} \mathrm{C}(\alpha$, $n)^{16} \mathrm{O}$ reaction. At low burning temperatures around $k T=8 \mathrm{keV}$, this rate is rather uncertain since it is extrapolated from experimental data at higher energies Denker et al. 1995). Would the rate be substantially lower, part of the ${ }^{13} \mathrm{C}$ nuclei would remain unburned and engulfed by the successive thermal pulse. In this case, the remaining ${ }^{13} \mathrm{C}$ would be burnt at higher temperature, substantially affecting the final abundance pattern.

Therefore, test calculations have been performed by reducing the rate of Denker et al. (1995) by factors of 2 and 10. The results show that also for the extreme case all the ${ }^{13} \mathrm{C}$ would be burnt radiatively due to the progressive increase of temperature and density in the pocket just prior to the thermal instability. Of course, the time evolution and the peak value of the neutron density would be different, but these variations would cause no significant effect on the results.

The rate of the ${ }^{22} \mathrm{Ne}(\alpha, n){ }^{25} \mathrm{Mg}$ reaction exhibits large uncertainties at $s$-process temperatures due to the possible existence of a low-lying resonance, which could substantially enhance the rate (Käppeler et al. 1994). Accordingly, a series of calculations was performed for the model star, varying the rate from the lower limit, where the possible 
contribution of the $633 \mathrm{keV}$ resonance was excluded, to the upper limit, which included this resonance in toto.

In all calculations, the standard deviation for the set of unbranched normalization isotopes remains less than 3\%, except for the most extreme case. As far as the branchings are concerned, it has to be stressed that the clear distinction of temperature and neutron density effects - which is made in the classical approach - makes no sense for the stellar model, where the time-dependent temperature profile is inherently provided by the evolutionary code. Accordingly, it depends only on the stellar mass and metallicity and varies with pulse number. Therefore, an increase in peak temperature implies a corresponding increase in the peak neutron density, regardless of adopted ${ }^{22} \mathrm{Ne}(\alpha, n)^{25} \mathrm{Mg}$ rate.

While the ${ }^{22} \mathrm{Ne}(\alpha, n)^{25} \mathrm{Mg}$ rate has no significant impact for the unbranched normalization isotopes, it governs the abundance patterns in the $s$-process branchings. It was found that the branchings represented by the isotope pairs ${ }^{87} \mathrm{Rb} /{ }^{87} \mathrm{Sr},{ }^{96} \mathrm{Zr} /{ }^{96} \mathrm{Mo}$, ${ }^{134} \mathrm{Ba} /{ }^{136} \mathrm{Ba},{ }^{152} \mathrm{Gd} /{ }^{154} \mathrm{Gd}$, and ${ }^{176} \mathrm{Lu} /{ }^{176} \mathrm{Hf}$ are most sensitive to the ${ }^{22} \mathrm{Ne}(\alpha, n){ }^{25} \mathrm{Mg}$ rate. Overall, the ${ }^{22} \mathrm{Ne}(\alpha, n)^{25} \mathrm{Mg}$ burst modifies the distribution produced by the first neutron source, but this remains a "local" process that does not reach beyond the magic barriers. Highly non solar patterns were obtained for all isotopes listed above using rates including more than $50 \%$ of the hypothetical $633 \mathrm{keV}$ resonance. These cases yield also unacceptable values for somewhat less sensitive branchings, like those bypassing ${ }^{170} \mathrm{Yb}$ and ${ }^{192} \mathrm{Pt}$. As for ${ }^{142} \mathrm{Nd}$, an increasing ${ }^{22} \mathrm{Ne}(\alpha, n){ }^{25} \mathrm{Mg}$ rate leads to a depletion of this nucleus in the neutron density maximum, resulting in a progressive decrease of the ${ }^{142} \mathrm{Nd} /{ }^{150} \mathrm{Sm}$ ratio.

The best reproduction of the solar branching patterns is obtained with the recommended rate of Käppeler et al. (1994), after excluding the hypothetical contribution of the 633 kev resonance. Therefore, this rate was considered as a "standard" choice, although any value between the lower limit to the recommended value of Käppeler et al. (1994) still 
provides satisfactory results. Of course, the intention of this analysis is not to constrain the ${ }^{22} \mathrm{Ne}(\alpha, n)^{25} \mathrm{Mg}$ rate, since the fine-tuning is dependent on the model star, but to study the sensitivity of the results with respect to this uncertain rate.

With the standard choice for the ${ }^{22} \mathrm{Ne}(\alpha, n){ }^{25} \mathrm{Mg}$ rate, the ${ }^{13} \mathrm{C}(\alpha, n){ }^{16} \mathrm{O}$ neutron burst was investigated by varying the quantity of ${ }^{13} \mathrm{C}$ in the pocket. The best fit to the solar $s$ abundances was obtained by Gallino et al. (1998) with an average ${ }^{13} \mathrm{C}$ mass fraction of $6 \times 10^{-3}$. A series of test calculations was performed, by keeping the same slope of the ${ }^{13} \mathrm{C}$ pocket as in Gallino et al. (1998) but varying within a factor 1.5 up and down the total amount of ${ }^{13} \mathrm{C}$ nuclei present in the pocket (and using the standard stellar model for $2 M_{\odot}$, $\left.Z=1 / 2 Z_{\odot}, \eta=0.75\right)$, a range that relates to a reasonable representation of the main component.

As expected, the $s$-process yields in the investigated range are correlated with the amount of ${ }^{13} \mathrm{C}$ in the pocket, changing from $40 \%$ to $170 \%$ compared to the best representation. Within these limits the $s$-abundance distribution is fairly well reproduced over the entire mass range of the main component, except for the extreme cases. Larger variations than in the present test, however, lead to important deviations. Moreover, it turned out that the precise reproduction of ${ }^{134,136} \mathrm{Ba}$ abundances constitutes a more stringent constraint in the above test. Indeed, both nuclei are easily severely overproduced for low and high values of ${ }^{13} \mathrm{C}$. Accordingly, this reduces the acceptable ${ }^{13} \mathrm{C}$ values to a range of $\pm 10 \%$ around the best fit case. A similar lower limit is obtained from the significant overproduction of all isotopes below $A \sim 120$. 


\subsection{Uncertainties due to the evolutionary models}

The most crucial points are the mass fractions $\Delta m$ dredged up after each thermal instability and the mass-loss rate. Both problems are somehow related, because the number of thermal instabilities with TDU is determined by the mass loss rate. According to Straniero et al. (1997) the TDU ceases when the envelope mass becomes smaller than about $0.5 M_{\odot}$. The evolutionary code FRANEC finds TDU for stellar masses above $1.5 M_{\odot}$ at

solar metallicity. The efficiency of the phenomenon is still a very debated matter (Frost \& Lattanzio 1996,1998). In the present context, we consider only the uncertainties related to the FRANEC code.

The determination of $\Delta m$ is the most difficult problem for stellar $s$-process models, which has a strong impact on Galactic chemical evolution. At present, the concepts for describing the $\mathrm{H}-\mathrm{He}$ interface, a very thin zone compared to the mass of the envelope, exhibit a number of persisting uncertainties. The calculated values for $\Delta m$ appear plausible due to the constraints from stellar observations (Busso, Gallino, \& Wasserburg 1999), but it is certainly difficult to derive the related uncertainties from first principles.

Another problem affecting the final $s$-process abundance distribution in the envelope is related to the uncertainty of the choice of the mass loss rate. However, an asymptotic $s$-process distribution is reached after a limited number of pulses, so that mass loss uncertainties affect mainly the total yield of $s$-processed material, and not much the shape of the distribution. This last, however, is sensitive to uncertainties in contributions from the small neutron exposure released by the ${ }^{22} \mathrm{Ne}(\alpha, n)^{25} \mathrm{Mg}$ source. Since the maximum bottom temperature increases from pulse to pulse, affecting the strength of the neutron burst, the cumulative $s$-process distribution in the envelope can in fact be influenced by whether the combined effects of recurrent TDU episodes and mass loss allow the material from the very last pulses to contribute or not. The TDU efficiency rises rapidly to an almost constant 
value until it drops when the envelope mass becomes sufficiently low. The effect of a larger mass loss rate was, therefore, studied by omitting the three last pulses, which have the highest temperatures at the bottom of the He burning zone. The resulting effect on the $s$-process abundances was negligible. The only noticeable difference of about $8 \%$ was found for ${ }^{96} \mathrm{Zr}$, which is very sensitive to the neutron density.

\subsection{Influence of the initial stellar mass}

Though the nucleosynthesis yields of the investigated stars from 1.5 to $3 M_{\odot}$ span a factor of two, the respective abundance distributions are rather similar, an important result with respect to Galactic evolution. Moderate differences in the $s$ abundances are due to the higher temperatures reached during the thermal pulses in more massive stars (e.g. in the $3 M_{\odot}$ model). This implies a stronger influence of the ${ }^{22} \mathrm{Ne}$ source, which affects the contribution of the second burst to the total neutron exposure as well as the abundance patterns of several branchings.

The effect on the branchings is of the order of $5 \%$, except for ${ }^{96} \mathrm{Zr}$, which increases by a factor two, reaching $80 \%$ of the average overabundance of the $s$-only isotopes in the 3 $M_{\odot}$ star.

\section{Relevant branchings in the $s$-process path}

\subsection{Nd-Pm-Sm}

The abundance of ${ }^{148} \mathrm{Sm}$ is determined by the branchings at ${ }^{147} \mathrm{Nd}$ and ${ }^{147,148} \mathrm{Pm}$, while the short lifetimes of ${ }^{148} \mathrm{Nd}$ and ${ }^{149} \mathrm{Pm}$ leave the second $s$-only samarium isotope, ${ }^{150} \mathrm{Sm}$, virtually unbranched. For the involved Nd and Pm branching points, the beta-decay rates 
are almost independent of $T$ and $n_{e}$. Although experimental data for the cross sections of the unstable Pm isotopes are not yet available, the accurate measurements for Nd Toukan et al. 1995) and Sm (Wisshak et al. 1993) isotopes and the accurate solar abundances of these elements (1.3\%, Anders \& Grevesse 1989) allow the most constraining determination of the effective neutron density $n_{n}=4.1 \pm 0.6 \times 10^{8} \mathrm{~cm}^{-3}$ (Toukan et al. 1995) via the classical approach. This result is indicated in Fig. 4 (top panel) by the shaded band.

In the stellar model, the mild neutron densities of the ${ }^{13} \mathrm{C}$ source are not sufficient for the reaction flow to bypass ${ }^{148} \mathrm{Sm}$, thus producing it abundantly. The opposite situation prevails, when the neutron density in the second burst reaches up to $10^{10} \mathrm{~cm}^{-3}$. Then, ${ }^{148} \mathrm{Sm}$ is almost completely bypassed, leading to a strong depletion (Fig. 4, middle panel). However, during the decline of the neutron density, the branchings to ${ }^{148} \mathrm{Sm}$ are restored. Eventually, the final value is established during the freeze-out of the abundance pattern. Thus, in the stellar model this branching depends on the neutron density in a two-fold way: from the peak neutron density, which causes the initial destruction and explains why different stellar masses produce small but noticeably different results, and - predominantly - from the freeze-out of the neutron supply, which determines the final ${ }^{148} \mathrm{Sm} /{ }^{150} \mathrm{Sm}$ ratio.

It was pointed out by Cosner, Iben, \& Truran (1980) and Käppeler et al. (1982) that the effective parameters obtained by the classical analysis have to be considered as local features, which, therefore, could be compared to the freeze-out conditions obtained by the stellar models. Reasonable agreement was found for the superseded stellar models when ${ }^{13} \mathrm{C}$ was assumed to burn convectively (Käppeler et al. 1990). The most intuitive criterion for the determination of the freeze-out conditions is to consider the moment in which the isotopic abundances reach the $90 \%$ of their final values. The more complex criterion proposed by Cosner, Iben, \& Truran (1980) was also considered, but with negligible differences. According to Fig. 4, the neutron density at freeze-out obtained with the present 
stellar model is $\approx 1 \times 10^{8} \mathrm{~cm}^{-3}$, considerably lower than the phenomenological estimates. This emphasizes that the effective parameters of the classical approach are certainly not adequate to describe the dynamical s-process conditions during the AGB phase.

\subsection{Sm-Eu-Gd}

The abundance of the $s$-only isotope ${ }^{152} \mathrm{Gd}$ is determined by branchings at ${ }^{151} \mathrm{Sm}$ and ${ }^{152} \mathrm{Eu}$, while ${ }^{154} \mathrm{Gd}$ is partly bypassed due to a branching at ${ }^{154} \mathrm{Eu}$. The $\beta$-decay rates of ${ }^{151} \mathrm{Sm}$ and ${ }^{154} \mathrm{Eu}$ are extremely sensitive to the temperature, in particular that of ${ }^{151} \mathrm{Sm}$, which is enhanced by bound state decays (Takahashi \& Yokoi 1987). In both cases, the effect of the electron density on the stellar decay rates has also to be considered.

Since both the $s$-only isotopes are partially bypassed, the reaction flow is normalized at ${ }^{150} \mathrm{Sm}$. This introduces an uncertainty of only $1.3 \%$, since the relative elemental abundances are well defined in the region of the rare earth elements (Anders \& Grevesse 1989). The main difficulty in determining the effective $s$-process temperature from these branchings is due to the rather uncertain $p$-process contribution to ${ }^{152} \mathrm{Gd}$. The empirical extrapolation from neighboring $p$-only nuclei suggests this contribution to reach $\sim 30 \%$, whereas the most recent model calculations yield only a value of $~ 12 \%$ (Rayet, Prantzos, \& Arnould 1990; Prantzos et al. 1990; Howard, Meyer, \& Woosley 1991; Rayet 1991; Howard 1991; Rayet et al. 1995). Furthermore, a contribution of $\sim 6 \%$ to ${ }^{152} \mathrm{Gd}$ is expected from the $s$ process in massive stars (Raiteri et al. 1993), even if these calculations need to be updated.

The branchings to ${ }^{152} \mathrm{Gd}$ and ${ }^{154} \mathrm{Gd}$ differ significantly. While $\sim 90 \%$ of the flow is bypassing ${ }^{152} \mathrm{Gd}$, which means that $f_{\beta}$ is dominated by the $\beta$-decay rates rather than by the neutron capture rates, the branching to ${ }^{154} \mathrm{Gd}$ exhibits the opposite behavior. The neutron capture cross sections of all stable nuclei have been recently remeasured with considerably 
improved accuracy (Wisshak et al. 1993; Wisshak et al. 1995; Jaag et al. 1999). New calculations have been performed for the branch-point nuclei (Toukan et al. 1995; Jaag et al. 1999) including an evaluation of the stellar enhancement factors (Jaag et al. 1999). For the Eu isotopes, these results are found to be significantly different as compared to the earlier calculations of Holmes et al. (1976) and Harris (1981).

Despite of the remaining uncertainties, the range of possible $s$-process temperatures was constrained by the classical analysis, corresponding to thermal energies between $k T=$ 28 and $33 \mathrm{keV}$ (Wisshak et al. 1993).

On the contrary to what happens in the classical scenario, the situation in the stellar model is rather complex. During the ${ }^{13} \mathrm{C}$-burning phase, the reaction flow is almost totally passing through ${ }^{152} \mathrm{Gd}$, because of the low neutron density and since the lifetime of ${ }^{151} \mathrm{Sm}$ is strongly reduced already at $\sim 8 \mathrm{keV}$. Accordingly, in this phase ${ }^{154} \mathrm{Gd}$ results mainly from neutron captures on ${ }^{152} \mathrm{Gd}$ and ${ }^{153} \mathrm{Gd}$, leading to a constant ${ }^{152} \mathrm{Gd} /{ }^{154} \mathrm{Gd}$ ratio. Therefore, it is only during the second neutron burst that the thermometer-like property of these branchings becomes apparent. Due to the high peak neutron density the reaction flow essentially bypasses ${ }^{152} \mathrm{Gd}$, which is almost totally destroyed, and not efficiently restored during freeze-out so that the final abundance remains relatively small.

${ }^{154} \mathrm{Gd}$ is less depleted during the peak neutron density of the second burst, reaching about $10 \%$ of its abundance prior to the thermal instability (Fig. 4, bottom panel). This is so because the main reaction flow shifts only from the Gd to the Eu isotopes. During freeze-out, this shift is reversed, leading to the relatively high value of the final ${ }^{154} \mathrm{Gd}$ abundance. 


\subsection{Other branchings}

Apart from the two examples discussed in detail, there are a number of other important branchings along the $s$-process path, i.e. those to the $s$-only isotopes ${ }^{164} \mathrm{Er},{ }^{176} \mathrm{Lu} /{ }^{176} \mathrm{Hf}$, ${ }^{186} \mathrm{Os}$, and ${ }^{192} \mathrm{Pt}$. Except for the very complicated case at $A=176$, the respective abundance patterns are well reproduced by the stellar model as can be seen from the regular overproduction factors of the related s-only nuclei (Fig. 3).

Therefore, it can be concluded, that the very sensitive test via the $s$-process branchings has led to another confirmation of the stellar model.

\section{7. $\quad r$-Residuals}

The success of the stellar model in reproducing the $s$-process pattern of the heavy elements opens the possibility for decomposing the solar abundance distribution into the respective $s$ - and $r$-process components. As far as the $p$ process is concerned, even the refined $s$-process analyses based on accurate cross sections are not yet reliable enough to obtain quantitative estimates for the much smaller $p$-process yields.

EDITOR: PLACE TABLE 2 HERE.

\section{EDITOR: PLACE FIGURE 5 HERE.}

Although the decomposition into $s$ - and $r$-process components requires a full calculation for the $s$ abundances integrated over the Galactic evolution, the present stellar model results appear already to be a reasonable representation of the $s$-process part (Fig. 3). Therefore, the residuals $N_{r}=N_{\odot}-N_{s}$ were calculated using the $s$ abundances obtained via 
the classical approach and as the arithmetic average of the 1.5 and $3 \mathrm{M}_{\odot}$ models at $Z=$ $1 / 2 Z_{\odot}$ best reproducing the main component.

The results are listed in Table 2 for the adopted stellar model (columns 3 to 6 ) and for the classical approach (columns 7 to 10). Both calculated $s$ distributions were normalized using the solar abundance of ${ }^{150} \mathrm{Sm}$ as a reference. Accordingly, the $r$ residuals are expected to reflect the solar $r$ distribution. The uncertainties $\delta N_{s}$ and $\delta N_{r}$ are determined by the uncertainties of the respective cross sections and solar abundances. Since stellar spectroscopy often yields elemental abundances the corresponding values are included in Table 2 for each element by summation over the isotopic data. Relative overabundances in the calculated distributions with respect to solar are indicated by boldface numbers.

In the mass region of the main component, i.e. between $\mathrm{Sr}$ and $\mathrm{Tl}$, the comparison of both distributions in Fig. 5 shows pretty good agreement. This consistency in the $r$ residuals is reached since the uncertain abundances of some $s$-only isotopes are replaced by the abundances of their $r$-only isobars. Note, that the $r$ residuals for $\mathrm{Pb}$, and $\mathrm{Bi}$, are omitted because these isotopes are significantly produced in low metallicity stars (see Gallino et al. 1998).

In case of the classical model, the $r$ residuals have been complemented below ${ }^{88} \mathrm{Sr}$ by considering the parameterized weak component of Beer, Walter, \& Käppeler (1992). Though this schematic approach does not relate to any realistic model, it accounts for the abundances of the respective $s$-only nuclei and may be useful for comparison with $r$-process calculations.

In summary, the $r$ residuals constitute a fairly robust distribution, which can well be used for comparison with $r$-process model calculations or astronomical observations. 


\section{Summary and conclusions}

The $s$ abundances for the main component in the mass region $88<A<208$ were investigated with updated $(n, \gamma)$ rates by means of the classical approach and with refined stellar models for AGB stars in the range between 1.5 and $3 M_{\odot}$. Both models were found to reproduce the ensemble of those $s$-only isotopes, which are not affected by branchings in the reaction path, i.e. ${ }^{100} \mathrm{Ru},{ }^{110} \mathrm{Cd},{ }^{116} \mathrm{Sn},{ }^{122,123,124} \mathrm{Te},{ }^{150} \mathrm{Sm}$, and ${ }^{160} \mathrm{Dy}$, with a mean deviation of a few percent.

However, striking discrepancies between the two models were found for a few isotopes. The most significant of these refers to ${ }^{142} \mathrm{Nd}$. The abundance of ${ }^{142} \mathrm{Nd}$ is affected by branchings in the neutron capture path at ${ }^{141} \mathrm{Ce}$ and ${ }^{142} \mathrm{Pr}$, which are almost independent of the $s$-process temperature and electron density (Takahashi \& Yokoi 1987). These branchings, and consequently the $s$ abundance of ${ }^{142} \mathrm{Nd}$ could be reliably characterized by means of a complete set of recently reported, accurate $(n, \gamma)$ cross sections. The significant revision of the ${ }^{142} \mathrm{Nd}$ cross section eliminated the problem of a persisting underproduction of this isotope by the stellar models (Gallino et al. 1998). In turn, the new data imply that the classical model is now producing an inherent overabundance of ${ }^{142} \mathrm{Nd}$ with respect to the average of the other $s$-only nuclei, exceeding the respective $1 \sigma$-uncertainties by a

factor 6. Similar but less stringent discrepancies were also found earlier for ${ }^{136} \mathrm{Ba}$ Voss et al. 1994) and ${ }^{116} \mathrm{Sn}$ (Wisshak et al. 1996). This must be considered as evidence that the static assumptions for the $s$-process site, which are implicit for the classical model, are not realistic. The same argument applies to other phenomenological models.

The stellar models based on recent evolutionary calculations of low mass AGB stars are found increasingly successful in reproducing the solar distribution of $s$-nuclei. In the light of the improved cross sections, these models were found to reproduce the observed $s$ abundances within the respective cross section and/or abundance uncertainties, despite the 
complex scenario and a number of remaining problems. Another example along these lines are the large abundances in the Kr-Rb-Sr region predicted by the classical approach, which are incompatible with the additional contributions from the weak component and from the $r$ process. This problem does not exist in the stellar model, where the $s$-process production is much less efficient in this mass region, in full agreement with the low Rb/Sr ratios from spectroscopic observations (Lambert et al. 1995). This success not only refers to the overall $s$ distribution but is also confirmed by the proper reproduction of the abundance pattern of the branchings in the reaction path, which represent a sensitive test for any $s$-process model. So far, only a few branchings are determined with sufficient accuracy so that they can be used to derive sufficiently stringent constraints. Among these are the branchings in the region of the REE, which all have well defined abundances. In particular, this has been demonstrated by the branchings characterized by the $s$-nuclei of neodymium, samarium, and gadolinium.

In terms of the chemical evolution of the Galaxy the analysis of the $s$-process yields from AGB stars of different mass and metallicity (Travaglio et al. 1999; Raiteri et al. 1999) confirms that the elements heavier than $\mathrm{Ba}$ including the large ${ }^{208} \mathrm{~Pb}$ abundance - which required the postulation of a separate strong component in the classical approach (Käppeler, Beer, \& Wisshak 1989) - are naturally produced by AGB stars in the investigated mass range as anticipated by Gallino et al. (1998). However, a better description of the $s$ abundances is required in the mass region $88<A<130$ where the present yields are somewhat too low. This difference may well be accounted for by the $s$ contributions from intermediate mass AGB stars (Vaglio et al. 1999; Gallino et al. 1999).

It is a pleasure to thank F.-K. Thielemann and G. J. Wasserburg for stimulating discussions and suggestions.

This work was partly supported by a grant of italian MURST Cofin 98 . 
Table 1. MAXWELLIAN AVERAGED NEUTRON CAPTURE CROSS SECTIONS

\begin{tabular}{|c|c|c|c|c|}
\hline \multirow[t]{2}{*}{ NuCLEUS } & \multicolumn{3}{|c|}{$\langle\sigma\rangle($ mbarn $)$} & \multirow[t]{2}{*}{ REF. } \\
\hline & $10 \mathrm{keV}$ & $25 \mathrm{keV}$ & $30 \mathrm{keV}$ & \\
\hline \multirow[t]{2}{*}{${ }^{140} \mathrm{Ce}$} & $\cdots$ & $12.0 \pm 0.4$ & $11.0 \pm 0.4$ & Käppeler et al. 1996 \\
\hline & $16.9 \pm 0.8$ & $11.6 \pm 0.6$ & $10.6 \pm 0.5$ & Beer et al. 1992 \\
\hline \multirow[t]{2}{*}{${ }^{141} \mathrm{Ce}$} & 186 & 102 & 91.0 & Käppeler et al. $1996^{a}$ \\
\hline & 357 & $\cdots$ & 167 & Beer et al. $1992^{\mathrm{a}}$ \\
\hline \multirow[t]{2}{*}{${ }^{142} \mathrm{Ce}$} & $\cdots$ & $30.8 \pm 1.0$ & $28.3 \pm 1.0$ & Käppeler et al. 1996 \\
\hline & $\cdots$ & $\cdots$ & $19.6 \pm 1.1$ & Beer \& Käppeler 1980 \\
\hline \multirow[t]{2}{*}{${ }^{141} \operatorname{Pr}$} & $246.5 \pm 6.5$ & $126.3 \pm 1.7$ & $111.4 \pm 1.4$ & Voss et al. 1999 \\
\hline & 196 & 109 & 97 & Käppeler et al. $1996^{\mathrm{a}}$ \\
\hline \multirow[t]{2}{*}{${ }^{142} \mathrm{Pr}$} & 684 & 343 & 297 & Käppeler et al. $1996^{a}$ \\
\hline & $\cdots$ & $\cdots$ & 932 & Holmes et al. $1976^{\mathrm{a}}$ \\
\hline \multirow[t]{3}{*}{${ }^{142} \mathrm{Nd}$} & $65.1 \pm 1.9$ & $38.4 \pm 0.8$ & $35.0 \pm 0.7$ & Wisshak et al. 1998b \\
\hline & $65.8 \pm 2.9$ & $\cdots$ & $36.6 \pm 3.0$ & Guber et al. 1997 \\
\hline & $95.8 \pm 8.3$ & $51.9 \pm 4.5$ & $46.0 \pm 4.0$ & Beer et al. 1992 \\
\hline \multirow[t]{2}{*}{${ }^{143} \mathrm{Nd}$} & $528.3 \pm 12.0$ & $275.7 \pm 3.7$ & $244.6 \pm 3.1$ & Wisshak et al. 1998a \\
\hline & $508 \pm 21$ & $274 \pm 11$ & $242 \pm 10$ & Beer et al. 1992 \\
\hline
\end{tabular}


Table 1-Continued

\begin{tabular}{|c|c|c|c|c|}
\hline \multirow[t]{2}{*}{ NuClEus } & \multicolumn{3}{|c|}{$\langle\sigma\rangle(\mathrm{mbarn})$} & \multirow[t]{2}{*}{ REF. } \\
\hline & $10 \mathrm{keV}$ & $25 \mathrm{keV}$ & $30 \mathrm{keV}$ & \\
\hline \multirow[t]{3}{*}{${ }^{144} \mathrm{Nd}$} & $147.0 \pm 4.5$ & $88.5 \pm 1.7$ & $81.3 \pm 1.5$ & Wisshak et al. $1998 b$ \\
\hline & $122.2 \pm 5.4$ & $\ldots$ & $73.2 \pm 6.1$ & Guber et al. 1997 \\
\hline & $232 \pm 13$ & $123 \pm 7$ & $108 \pm 6$ & Beer et al. 1992 \\
\hline
\end{tabular}

${ }^{a}$ Calculated values 
Table 2. S-PROCESS YIELDS AND RESIDUALS FOR THE STELLAR AND THE CLASSICAL MODEL

\begin{tabular}{|c|c|c|c|c|c|c|c|c|c|}
\hline \multirow{2}{*}{ NuClEus } & \multirow{2}{*}{$\begin{array}{c}\text { SOLAR } \\
\text { ABUNDANCE }^{\mathrm{b}}\end{array}$} & \multicolumn{4}{|c|}{ Stellar MODEL ${ }^{a}$} & \multicolumn{4}{|c|}{ ClaSSICAL MODEL $^{\mathrm{a}}$} \\
\hline & & $N_{s}^{\text {main }}$ & $\begin{array}{c}\delta N_{s}^{\text {main }} \\
(\%)\end{array}$ & $N_{r}$ & $\begin{array}{l}\delta N_{r} \\
(\%)\end{array}$ & $N_{s}^{\text {main }}$ & $\begin{array}{c}\delta N_{s}^{\operatorname{main}} \\
(\%)\end{array}$ & $N_{r}$ & $\begin{array}{l}\delta N_{r} \\
(\%)\end{array}$ \\
\hline${ }^{63} \mathrm{Cu}$ & $3.61 \mathrm{E}+02$ & $2.95 \mathrm{E}+00$ & 18.6 & & & $1.73 \mathrm{E}+01$ & 18.6 & & \\
\hline${ }^{65} \mathrm{Cu}$ & $1.61 \mathrm{E}+02$ & $2.04 \mathrm{E}+00$ & 14.5 & & & $9.11 \mathrm{E}+00$ & 14.5 & & \\
\hline $\mathbf{C u}^{\mathrm{d}}$ & & $1.0 \%$ & & & & $5.1 \%$ & & & \\
\hline${ }^{64} \mathrm{Zn}$ & $6.13 \mathrm{E}+02$ & $9.21 \mathrm{E}-01$ & 9.5 & & & $4.12 \mathrm{E}+00$ & 9.5 & & \\
\hline${ }^{66} \mathrm{Zn}$ & $3.52 \mathrm{E}+02$ & $3.44 \mathrm{E}+00$ & 9.6 & & & $1.42 \mathrm{E}+01$ & 9.6 & & \\
\hline${ }^{67} \mathrm{Zn}$ & $5.17 \mathrm{E}+01$ & $7.78 \mathrm{E}-01$ & 10.7 & & & $3.19 \mathrm{E}+00$ & 10.7 & & \\
\hline${ }^{68} \mathrm{Zn}$ & $2.36 \mathrm{E}+02$ & $6.78 \mathrm{E}+00$ & 13.3 & & & $2.17 \mathrm{E}+01$ & 13.3 & & \\
\hline${ }^{70} \mathrm{Zn}$ & $7.80 \mathrm{E}+00$ & $2.36 \mathrm{E}-02$ & 50.2 & & & $6.57 \mathrm{E}-3$ & 50.2 & & \\
\hline $\mathbf{Z n}^{\mathrm{d}}$ & & $0.9 \%$ & & & & $3.4 \%$ & & & \\
\hline${ }^{69} \mathrm{Ga}$ & $2.27 \mathrm{E}+01$ & $8.73 \mathrm{E}-01$ & 11.1 & & & $2.85 \mathrm{E}+00$ & 11.1 & $6.29 E+00^{c}$ & \\
\hline${ }^{71} \mathrm{Ga}$ & $1.51 \mathrm{E}+01$ & $8.35 \mathrm{E}-01$ & 9.0 & & & $4.25 \mathrm{E}+00$ & 9.0 & $0.00 E+00^{c}$ & \\
\hline $\mathbf{G a}^{\mathrm{d}}$ & & $4.5 \%$ & & & & $19 \%$ & & & \\
\hline${ }^{70} \mathrm{Ge}$ & $2.44 \mathrm{E}+01$ & $1.60 \mathrm{E}+00$ & 11.2 & & & $4.37 \mathrm{E}+00$ & 11.2 & & \\
\hline${ }^{72} \mathrm{Ge}$ & $3.26 \mathrm{E}+01$ & $2.47 \mathrm{E}+00$ & 29.7 & & & $6.28 \mathrm{E}+00$ & 29.7 & $8.12 E+00^{c}$ & \\
\hline${ }^{73} \mathrm{Ge}$ & $9.28 \mathrm{E}+00$ & $4.68 \mathrm{E}-01$ & 30.8 & & & $1.25 \mathrm{E}+00$ & 30.8 & $3.66 E+00^{c}$ & \\
\hline${ }^{74} \mathrm{Ge}$ & $4.34 \mathrm{E}+01$ & $2.62 \mathrm{E}+00$ & 14.7 & & & $6.11 \mathrm{E}+00$ & 14.7 & $2.50 E+01^{\mathrm{C}}$ & \\
\hline${ }^{76} \mathrm{Ge}$ & $9.28 \mathrm{E}+00$ & $5.52 \mathrm{E}-03$ & 12.6 & & & $3.17 \mathrm{E}-03$ & 12.6 & $9.28 E+00^{\mathrm{c}}$ & \\
\hline $\mathbf{G e}^{\mathrm{d}}$ & & $6.0 \%$ & & & & $15 \%$ & & & \\
\hline${ }^{75} \mathrm{As}$ & $6.56 \mathrm{E}+00$ & $3.02 \mathrm{E}-01$ & 12.6 & & & $5.84 \mathrm{E}-01$ & 12.6 & $4.44 E+00^{c}$ & \\
\hline $\mathbf{A} \mathbf{s}^{\mathrm{d}}$ & & $4.6 \%$ & & & & $8.9 \%$ & & & \\
\hline${ }^{76} \mathrm{Se}$ & $5.60 \mathrm{E}+00$ & $8.62 \mathrm{E}-01$ & 8.0 & & & $2.21 \mathrm{E}+00$ & 8.0 & & \\
\hline${ }^{77} \mathrm{Se}$ & $4.70 \mathrm{E}+00$ & $3.15 \mathrm{E}-01$ & 30.2 & & & $7.27 \mathrm{E}-01$ & 30.2 & $2.60 E+00^{\mathrm{c}}$ & \\
\hline${ }^{78} \mathrm{Se}$ & $1.47 \mathrm{E}+01$ & $1.57 \mathrm{E}+00$ & 21.0 & & & $3.44 \mathrm{E}+00$ & 21.0 & $6.84 E+00^{\mathrm{C}}$ & \\
\hline${ }^{80} \mathrm{Se}$ & $3.09 \mathrm{E}+01$ & $2.73 \mathrm{E}+00$ & 9.4 & & & $3.49 \mathrm{E}+00$ & 9.4 & $2.41 E+01^{\mathrm{c}}$ & \\
\hline${ }^{82} \mathrm{Se}$ & $5.70 \mathrm{E}+00$ & $3.39 \mathrm{E}-03$ & 50.4 & & & $1.82 \mathrm{E}-03$ & 50.4 & $5.70 E+00^{c}$ & \\
\hline $\mathbf{S e}^{\mathrm{d}}$ & & $8.9 \%$ & & & & $16 \%$ & & & \\
\hline${ }^{79} \mathrm{Br}$ & $5.98 \mathrm{E}+00$ & $5.22 \mathrm{E}-01$ & 19.4 & & & $9.58 \mathrm{E}-01$ & 19.4 & $3.51 E+00^{\mathrm{c}}$ & \\
\hline${ }^{81} \mathrm{Br}$ & $5.82 \mathrm{E}+00$ & $5.41 \mathrm{E}-01$ & 19.4 & & & $5.64 \mathrm{E}-01$ & 19.4 & $4.36 E+00^{c}$ & \\
\hline $\mathrm{Br}^{\mathrm{d}}$ & & $9.0 \%$ & & & & $14 \%$ & & & \\
\hline
\end{tabular}


Table 2-Continued

\begin{tabular}{|c|c|c|c|c|c|c|c|c|c|}
\hline \multirow{2}{*}{ NuCleus } & \multirow{2}{*}{$\begin{array}{c}\text { SOLAR } \\
\text { ABUNDANCE }^{\mathrm{b}}\end{array}$} & \multicolumn{4}{|c|}{ STELLAR MODEL ${ }^{\mathrm{a}}$} & \multicolumn{4}{|c|}{ ClaSSICAL MODEL $^{\mathrm{a}}$} \\
\hline & & $N_{s}^{\text {main }}$ & $\begin{array}{c}\delta N_{s}^{\text {main }} \\
(\%)\end{array}$ & $N_{r}$ & $\begin{array}{l}\delta N_{r} \\
(\%)\end{array}$ & $N_{s}^{\text {main }}$ & $\begin{array}{c}\delta N_{s}^{\text {main }} \\
(\%)\end{array}$ & $N_{r}$ & $\begin{array}{l}\delta N_{r} \\
(\%)\end{array}$ \\
\hline${ }^{80} \mathrm{Kr}$ & $9.99 \mathrm{E}-01$ & $1.17 \mathrm{E}-01$ & 18.9 & & & $5.64 \mathrm{E}-01$ & 18.9 & & \\
\hline${ }^{82} \mathrm{Kr}$ & $5.15 \mathrm{E}+00$ & $1.91 \mathrm{E}+00$ & 19.6 & & & $3.38 \mathrm{E}+00$ & 19.6 & & \\
\hline${ }^{83} \mathrm{Kr}$ & $5.16 \mathrm{E}+00$ & $6.50 \mathrm{E}-01$ & 19.1 & & & $1.12 \mathrm{E}+00$ & 19.1 & $3.27 E+00^{c}$ & \\
\hline${ }^{84} \mathrm{Kr}$ & $2.57 \mathrm{E}+01$ & $3.54 \mathrm{E}+00$ & 21.5 & & & $8.21 \mathrm{E}+00$ & 21.5 & $1.68 E+01^{\mathrm{c}}$ & \\
\hline${ }^{86} \mathrm{Kr}$ & $7.84 \mathrm{E}+00$ & $2.12 \mathrm{E}+00$ & 18.1 & & & $64 \%{ }^{\mathrm{e}}$ & 18.1 & & \\
\hline $\mathbf{K} \mathbf{r}^{\mathrm{d}}$ & & $19 \%$ & & & & $47 \%$ & & & \\
\hline${ }^{85} \mathrm{Rb}$ & $5.12 \mathrm{E}+00$ & $8.36 \mathrm{E}-01$ & 7.6 & & & $2.14 \mathrm{E}+00$ & 7.6 & $2.75 E+00^{c}$ & \\
\hline${ }^{87} \mathrm{Rb}$ & $2.11 \mathrm{E}+00$ & $7.46 \mathrm{E}-01$ & 11.7 & & & $66 \%$ & 11.7 & & \\
\hline $\mathbf{R} \mathbf{b}^{\mathrm{d}}$ & & $22 \%$ & & & & $59 \%$ & & & \\
\hline${ }^{86} \mathrm{Sr}$ & $2.32 \mathrm{E}+00$ & $1.09 \mathrm{E}+00$ & 8.8 & & & $1.58 \mathrm{E}+00$ & 8.8 & & \\
\hline${ }^{87} \mathrm{Sr}$ & $1.51 \mathrm{E}+00$ & $7.60 \mathrm{E}-01$ & 8.9 & & & $1.12 \mathrm{E}+00$ & 8.9 & & \\
\hline${ }^{88} \mathrm{Sr}$ & $1.94 \mathrm{E}+01$ & $1.79 \mathrm{E}+01$ & 8.1 & & & $1.82 \mathrm{E}+01$ & 8.1 & $9.06 \mathrm{E}-01^{\mathrm{c}}$ & \\
\hline $\mathbf{S r}^{\mathrm{d}}$ & & $85 \%$ & & & & $90 \%$ & & & \\
\hline${ }^{89} \mathrm{Y}$ & $4.64 \mathrm{E}+00$ & $4.27 \mathrm{E}+00$ & 6.6 & $3.72 \mathrm{E}-01$ & 100 & $6.4 \%{ }^{\mathrm{e}}$ & 6.6 & & \\
\hline $\mathbf{Y}^{\mathrm{d}}$ & & $92 \%$ & & & & $100 \%$ & & & \\
\hline${ }^{90} \mathrm{Zr}$ & $5.87 \mathrm{E}+00$ & $4.24 \mathrm{E}+00$ & 12.4 & $1.63 \mathrm{E}+00$ & 39.7 & $4.01 \mathrm{E}+00$ & 12.4 & $1.86 \mathrm{E}+00$ & 33.5 \\
\hline${ }^{91} \mathrm{Zr}$ & $1.28 \mathrm{E}+00$ & $1.23 \mathrm{E}+00$ & 14.8 & $5.46 \mathrm{E}-02$ & 100 & $0.50 \%{ }^{\mathrm{e}}$ & 14.8 & & \\
\hline${ }^{92} \mathrm{Zr}$ & $1.96 \mathrm{E}+00$ & $1.83 \mathrm{E}+00$ & 13.7 & $1.28 \mathrm{E}-01$ & 100 & $8.3 \%^{\mathrm{e}}$ & 13.7 & & \\
\hline${ }^{94} \mathrm{Zr}$ & $1.98 \mathrm{E}+00$ & $8.2 \%^{\mathrm{e}}$ & 7.3 & & & $16 \%{ }^{\mathrm{e}}$ & 7.3 & & \\
\hline${ }^{96} \mathrm{Zr}$ & $3.20 \mathrm{E}-01$ & $1.76 \mathrm{E}-01$ & 7.3 & & & $1.63 \mathrm{E}-01$ & 7.3 & & \\
\hline $\mathbf{Z r}^{\mathrm{d}}$ & & $83 \%$ & & & & $82 \%$ & & & \\
\hline${ }^{93} \mathrm{Nb}$ & $6.98 \mathrm{E}-01$ & $5.96 \mathrm{E}-01$ & 2.4 & $1.02 \mathrm{E}-01$ & 16.8 & $2.0 \%{ }^{\mathrm{e}}$ & 2.4 & & \\
\hline $\mathbf{N b}^{\mathrm{d}}$ & & $85 \%$ & & & & $100 \%$ & & & \\
\hline${ }^{94} \mathrm{Mo}$ & $2.36 \mathrm{E}-01$ & $1.53 \mathrm{E}-03$ & 20.0 & & & $8.27 \mathrm{E}-05$ & 20.0 & & \\
\hline${ }^{95} \mathrm{Mo}$ & $4.06 \mathrm{E}-01$ & $2.25 \mathrm{E}-01$ & 6.9 & $1.81 \mathrm{E}-01$ & 15.0 & $2.24 \mathrm{E}-01$ & 6.9 & $1.82 \mathrm{E}-01$ & 14.9 \\
\hline${ }^{96} \mathrm{Mo}$ & $4.25 \mathrm{E}-01$ & $6.1 \%^{\mathrm{e}}$ & 7.1 & & & $16 \% \mathrm{e}^{\mathrm{e}}$ & 7.1 & & \\
\hline${ }^{97} \mathrm{Mo}$ & $2.44 \mathrm{E}-01$ & $1.43 \mathrm{E}-01$ & 6.9 & $1.01 \mathrm{E}-01$ & 16.4 & $1.67 \mathrm{E}-01$ & 6.9 & $7.72 \mathrm{E}-02$ & 22.9 \\
\hline${ }^{98} \mathrm{Mo}$ & $6.15 \mathrm{E}-01$ & $4.66 \mathrm{E}-01$ & 7.5 & $1.49 \mathrm{E}-01$ & 32.7 & $5.52 \mathrm{E}-01$ & 7.5 & $6.25 \mathrm{E}-02$ & 85.3 \\
\hline${ }^{100} \mathrm{Mo}$ & $2.46 \mathrm{E}-01$ & $9.42 \mathrm{E}-03$ & 21.3 & $2.37 \mathrm{E}-01$ & 5.8 & $0.00 \mathrm{E}-00$ & 21.3 & $2.46 \mathrm{E}-01$ & 5.5 \\
\hline $\mathbf{M o}^{\mathrm{d}}$ & & $50 \%$ & & & & $54 \%$ & & & \\
\hline
\end{tabular}


Table 2-Continued

\begin{tabular}{|c|c|c|c|c|c|c|c|c|c|}
\hline \multirow{2}{*}{ Nucleus } & \multirow{2}{*}{$\begin{array}{c}\text { SOLAR } \\
\text { ABUNDANCE }^{\mathrm{b}}\end{array}$} & \multicolumn{4}{|c|}{ STELLAR MODEL $^{\mathrm{a}}$} & \multicolumn{4}{|c|}{ 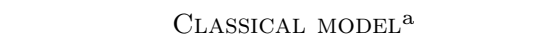 } \\
\hline & & $N_{s}^{\text {main }}$ & $\begin{array}{c}\delta N_{s}^{\text {main }} \\
(\%)\end{array}$ & $N_{r}$ & $\begin{array}{l}\delta N_{r} \\
(\%)\end{array}$ & $N_{s}^{\text {main }}$ & $\begin{array}{c}\delta N_{s}^{\text {main }} \\
(\%)\end{array}$ & $N_{r}$ & $\begin{array}{l}\delta N_{r} \\
(\%)\end{array}$ \\
\hline${ }^{99} \mathrm{Ru}$ & $2.36 \mathrm{E}-01$ & $6.69 \mathrm{E}-02$ & 50.3 & $1.69 \mathrm{E}-01$ & 21.3 & $6.94 \mathrm{E}-02$ & 50.3 & $1.67 \mathrm{E}-01$ & 22.3 \\
\hline${ }^{100} \mathrm{Ru}$ & $2.34 \mathrm{E}-01$ & $2.23 \mathrm{E}-01$ & 8.3 & & & $11 \%{ }^{\mathrm{e}}$ & 8.3 & & \\
\hline${ }^{101} \mathrm{Ru}$ & $3.16 \mathrm{E}-01$ & $4.83 \mathrm{E}-02$ & 6.7 & $2.68 \mathrm{E}-01$ & 6.5 & $5.38 \mathrm{E}-02$ & 6.7 & $2.62 \mathrm{E}-01$ & 6.7 \\
\hline${ }^{102} \mathrm{Ru}$ & $5.88 \mathrm{E}-01$ & $2.53 \mathrm{E}-01$ & 8.0 & $3.35 \mathrm{E}-01$ & 11.3 & $2.82 \mathrm{E}-01$ & 8.0 & $3.06 \mathrm{E}-01$ & 12.8 \\
\hline${ }^{104} \mathrm{Ru}$ & $3.48 \mathrm{E}-01$ & $9.52 \mathrm{E}-03$ & 8.2 & $3.38 \mathrm{E}-01$ & 5.6 & $3.75 \mathrm{E}-03$ & 8.2 & $3.44 \mathrm{E}-01$ & 5.5 \\
\hline $\mathbf{R} \mathbf{u}^{\mathrm{d}}$ & & $32 \%$ & & & & $37 \%$ & & & \\
\hline${ }^{103} \mathrm{Rh}$ & $3.44 \mathrm{E}-01$ & 4.67E-02 & 8.2 & $2.97 \mathrm{E}-01$ & 9.3 & $6.50 \mathrm{E}-02$ & 8.2 & $2.79 \mathrm{E}-01$ & 10.0 \\
\hline $\mathbf{R h}^{\mathrm{d}}$ & & $14 \%$ & & & & $19 \%$ & & & \\
\hline${ }^{104} \mathrm{Pd}$ & $1.55 \mathrm{E}-01$ & $5.7 \%^{\mathrm{e}}$ & 12.0 & & & $14 \%{ }^{\mathrm{e}}$ & 12.0 & & \\
\hline${ }^{105} \mathrm{Pd}$ & $3.10 \mathrm{E}-01$ & $4.27 \mathrm{E}-02$ & 8.3 & $2.67 \mathrm{E}-01$ & 7.8 & $4.31 \mathrm{E}-02$ & 8.3 & $2.67 \mathrm{E}-01$ & 7.8 \\
\hline${ }^{106} \mathrm{Pd}$ & $3.80 \mathrm{E}-01$ & $1.95 \mathrm{E}-01$ & 11.9 & $1.85 \mathrm{E}-01$ & 18.5 & $2.02 \mathrm{E}-01$ & 11.9 & $1.78 \mathrm{E}-01$ & 19.5 \\
\hline${ }^{108} \mathrm{Pd}$ & $3.68 \mathrm{E}-01$ & $2.40 \mathrm{E}-01$ & 11.9 & $1.28 \mathrm{E}-01$ & 29.2 & $2.46 \mathrm{E}-01$ & 11.9 & $1.22 \mathrm{E}-01$ & 31.1 \\
\hline${ }^{110} \mathrm{Pd}$ & $1.63 \mathrm{E}-01$ & $5.93 \mathrm{E}-03$ & 15.2 & $1.57 \mathrm{E}-01$ & 6.9 & $2.64 \mathrm{E}-04$ & 15.2 & $1.63 \mathrm{E}-01$ & 6.6 \\
\hline $\mathbf{P d}^{\mathrm{d}}$ & & $46 \%$ & & & & $47 \%$ & & & \\
\hline${ }^{107} \mathrm{Ag}$ & $2.52 \mathrm{E}-01$ & $3.77 \mathrm{E}-02$ & 4.2 & $2.14 \mathrm{E}-01$ & 3.5 & $3.80 \mathrm{E}-02$ & 4.2 & $2.14 \mathrm{E}-01$ & 3.5 \\
\hline${ }^{109} \mathrm{Ag}$ & $2.34 \mathrm{E}-01$ & $5.86 \mathrm{E}-02$ & 4.1 & $1.75 \mathrm{E}-01$ & 4.1 & $6.44 \mathrm{E}-02$ & 4.1 & $1.70 \mathrm{E}-01$ & 4.3 \\
\hline $\mathbf{A g}^{\mathrm{d}}$ & & $20 \%$ & & & & $21 \%$ & & & \\
\hline${ }^{108} \mathrm{Cd}$ & $1.43 \mathrm{E}-02$ & $1.61 \mathrm{E}-05$ & 18.4 & & & $2.20 \mathrm{E}-04$ & 18.4 & & \\
\hline${ }^{110} \mathrm{Cd}$ & $2.01 \mathrm{E}-01$ & $1.95 \mathrm{E}-01$ & 13.8 & & & $2.00 \mathrm{E}-01$ & 13.8 & & \\
\hline${ }^{111} \mathrm{Cd}$ & $2.06 \mathrm{E}-01$ & $4.87 \mathrm{E}-02$ & 13.4 & $1.57 \mathrm{E}-01$ & 9.5 & 4.61E-02 & 13.4 & $1.60 \mathrm{E}-01$ & 9.2 \\
\hline${ }^{112} \mathrm{Cd}$ & $3.88 \mathrm{E}-01$ & $2.05 \mathrm{E}-01$ & 14.4 & $1.83 \mathrm{E}-01$ & 21.2 & $2.05 \mathrm{E}-01$ & 14.4 & $1.83 \mathrm{E}-01$ & 21.3 \\
\hline${ }^{113} \mathrm{Cd}$ & $1.97 \mathrm{E}-01$ & $6.85 \mathrm{E}-02$ & 12.8 & $1.29 \mathrm{E}-01$ & 12.1 & $7.23 \mathrm{E}-02$ & 12.8 & $1.25 \mathrm{E}-01$ & 12.7 \\
\hline${ }^{114} \mathrm{Cd}$ & $4.63 \mathrm{E}-01$ & $2.95 \mathrm{E}-01$ & 16.8 & $1.68 \mathrm{E}-01$ & 34.5 & $3.68 \mathrm{E}-01$ & 16.8 & $9.45 \mathrm{E}-02$ & 73.0 \\
\hline${ }^{116} \mathrm{Cd}$ & $1.21 \mathrm{E}-01$ & $2.13 \mathrm{E}-02$ & 14.3 & $9.97 \mathrm{E}-02$ & 8.5 & $9.16 \mathrm{E}-03$ & 14.3 & $1.12 \mathrm{E}-01$ & 7.1 \\
\hline $\mathbf{C d}^{\mathrm{d}}$ & & $52 \%$ & & & & $57 \%$ & & & \\
\hline${ }^{113} \mathrm{In}$ & $7.90 \mathrm{E}-03$ & $5.59 \mathrm{E}-08$ & 11.0 & & & $3.63 \mathrm{E}-05$ & 11.0 & & \\
\hline${ }^{115} \mathrm{In}$ & $1.76 \mathrm{E}-01$ & $6.43 \mathrm{E}-02$ & 11.8 & $1.12 \mathrm{E}-01$ & 12.2 & $6.66 \mathrm{E}-02$ & 11.8 & $1.09 \mathrm{E}-01$ & 12.6 \\
\hline In $^{\mathrm{d}}$ & & $35 \%$ & & & & $36 \%$ & & & \\
\hline
\end{tabular}


Table 2-Continued

\begin{tabular}{|c|c|c|c|c|c|c|c|c|c|}
\hline \multirow{2}{*}{ Nucleus } & \multirow{2}{*}{$\begin{array}{c}\text { Solar } \\
\text { ABUNDANCE }^{\mathrm{b}}\end{array}$} & \multicolumn{4}{|c|}{ STELLAR MODEL $^{\mathrm{a}}$} & \multicolumn{4}{|c|}{ ClaAsSiCAl MOdel $^{\mathrm{a}}$} \\
\hline & & $N_{s}^{\text {main }}$ & $\begin{array}{c}\delta N_{s}^{\text {main }} \\
(\%)\end{array}$ & $N_{r}$ & $\begin{array}{l}\delta N_{r} \\
(\%)\end{array}$ & $N_{s}^{\text {main }}$ & $\begin{array}{c}\delta N_{s}^{\text {main }} \\
(\%)\end{array}$ & $N_{r}$ & $\begin{array}{l}\delta N_{r} \\
(\%)\end{array}$ \\
\hline${ }^{114} \mathrm{Sn}$ & $2.52 \mathrm{E}-02$ & $4.75 \mathrm{E}-06$ & 9.5 & & & $2.00 \mathrm{E}-04$ & 9.5 & & \\
\hline${ }^{115} \mathrm{Sn}$ & $1.29 \mathrm{E}-02$ & $3.06 \mathrm{E}-04$ & 9.7 & & & $1.60 \mathrm{E}-04$ & 9.7 & & \\
\hline${ }^{116} \mathrm{Sn}$ & $5.55 \mathrm{E}-01$ & $4.76 \mathrm{E}-01$ & 9.5 & & & $4.89 \mathrm{E}-1$ & 9.5 & & \\
\hline${ }^{117} \mathrm{Sn}$ & 2.93E-01 & $1.41 \mathrm{E}-01$ & 9.5 & $1.52 \mathrm{E}-01$ & 20.2 & $1.40 \mathrm{E}-01$ & 9.5 & $1.53 \mathrm{E}-01$ & 20.0 \\
\hline${ }^{118} \mathrm{Sn}$ & $9.25 \mathrm{E}-01$ & $6.67 \mathrm{E}-01$ & 9.4 & $2.58 \mathrm{E}-01$ & 41.7 & $6.86 \mathrm{E}-01$ & 9.4 & $2.39 \mathrm{E}-01$ & 45.5 \\
\hline${ }^{119} \mathrm{Sn}$ & $3.28 \mathrm{E}-01$ & $1.27 \mathrm{E}-01$ & 21.2 & $2.01 \mathrm{E}-01$ & 20.5 & $2.31 \mathrm{E}-01$ & 21.2 & $9.73 \mathrm{E}-02$ & 59.5 \\
\hline${ }^{120} \mathrm{Sn}$ & $1.25 \mathrm{E}+00$ & $9.77 \mathrm{E}-01$ & 9.5 & $2.68 \mathrm{E}-01$ & 55.7 & $1.07 \mathrm{E}+00$ & 9.5 & $1.78 \mathrm{E}-01$ & 86.7 \\
\hline${ }^{122} \mathrm{Sn}$ & $1.77 \mathrm{E}-01$ & $7.93 \mathrm{E}-02$ & 26.7 & $9.77 \mathrm{E}-02$ & 27.6 & $1.54 \mathrm{E}-02$ & 26.7 & $1.62 \mathrm{E}-01$ & 10.6 \\
\hline $\mathbf{S n}^{\mathrm{d}}$ & & $65 \%$ & & & & $70 \%$ & & & \\
\hline${ }^{121} \mathrm{Sb}$ & $1.77 \mathrm{E}-01$ & $6.78 \mathrm{E}-02$ & 18.2 & $1.09 \mathrm{E}-01$ & 31.3 & $7.22 \mathrm{E}-02$ & 18.2 & $1.05 \mathrm{E}-01$ & 32.9 \\
\hline${ }^{123} \mathrm{Sb}$ & $1.32 \mathrm{E}-01$ & $8.06 \mathrm{E}-03$ & 18.2 & $1.24 \mathrm{E}-01$ & 19.2 & $2.19 \mathrm{E}-03$ & 18.2 & $1.30 \mathrm{E}-01$ & 18.3 \\
\hline $\mathbf{S b}^{\mathrm{d}}$ & & $25 \%$ & & & & $24 \%$ & & & \\
\hline${ }^{122} \mathrm{Te}$ & $1.24 \mathrm{E}-01$ & $1.09 \mathrm{E}-01$ & 10.0 & & & $0.51 \%^{\mathrm{e}}$ & 10.0 & & \\
\hline${ }^{123} \mathrm{Te}$ & $4.28 \mathrm{E}-02$ & $3.83 \mathrm{E}-02$ & 10.0 & & & $2.9 \%^{\mathrm{e}}$ & 10.0 & & \\
\hline${ }^{124} \mathrm{Te}$ & $2.29 \mathrm{E}-01$ & $2.08 \mathrm{E}-01$ & 10.1 & & & $3.1 \%^{\mathrm{e}}$ & 10.1 & & \\
\hline${ }^{125} \mathrm{Te}$ & $3.42 \mathrm{E}-01$ & $6.80 \mathrm{E}-02$ & 10.0 & $2.74 \mathrm{E}-01$ & 12.7 & $8.41 \mathrm{E}-02$ & 10.0 & $2.58 \mathrm{E}-01$ & 13.7 \\
\hline${ }^{126} \mathrm{Te}$ & $9.09 \mathrm{E}-01$ & $3.68 \mathrm{E}-01$ & 10.1 & $5.41 \mathrm{E}-01$ & 18.2 & $4.29 \mathrm{E}-01$ & 10.1 & $4.80 \mathrm{E}-01$ & 21.0 \\
\hline${ }^{128} \mathrm{Te}$ & $1.53 \mathrm{E}+00$ & $2.47 \mathrm{E}-02$ & 10.4 & $1.50 \mathrm{E}+00$ & 10.2 & 4.03E-03 & 10.4 & $1.52 \mathrm{E}+00$ & 10.0 \\
\hline $\mathbf{T e}^{\mathrm{d}}$ & & $17 \%$ & & & & $19 \%$ & & & \\
\hline${ }^{127} \mathrm{I}$ & $9.00 \mathrm{E}-01$ & $4.75 \mathrm{E}-02$ & 21.5 & 8.53E-01 & 22.2 & $5.50 \mathrm{E}-02$ & 21.5 & $8.45 \mathrm{E}-01$ & 22.4 \\
\hline $\mathbf{I}^{\mathrm{d}}$ & & $5.3 \%$ & & & & $6.1 \%$ & & & \\
\hline${ }^{128} \mathrm{Xe}$ & $1.03 \mathrm{E}-01$ & $8.42 \mathrm{E}-02$ & 37.7 & & & $9.85 \mathrm{E}-02$ & 37.7 & & \\
\hline${ }^{129} \mathrm{Xe}$ & $1.28 \mathrm{E}+00$ & $4.03 \mathrm{E}-02$ & 21.8 & $1.24 \mathrm{E}+00$ & 20.7 & $4.57 \mathrm{E}-02$ & 21.8 & $1.23 \mathrm{E}+00$ & 20.8 \\
\hline${ }^{130} \mathrm{Xe}$ & $2.05 \mathrm{E}-01$ & $1.70 \mathrm{E}-01$ & 34.4 & & & $1.92 \mathrm{E}-01$ & 34.4 & & \\
\hline${ }^{131} \mathrm{Xe}$ & $1.02 \mathrm{E}+00$ & $6.55 \mathrm{E}-02$ & 26.8 & $9.55 \mathrm{E}-01$ & 21.5 & 7.39E-02 & 26.8 & $9.46 \mathrm{E}-01$ & 21.7 \\
\hline${ }^{132} \mathrm{Xe}$ & $1.24 \mathrm{E}+00$ & $4.16 \mathrm{E}-01$ & 21.6 & $8.24 \mathrm{E}-01$ & 32.0 & $4.92 \mathrm{E}-01$ & 21.6 & $7.48 \mathrm{E}-01$ & 36.1 \\
\hline${ }^{134} \mathrm{Xe}$ & $4.59 \mathrm{E}-01$ & $2.22 \mathrm{E}-02$ & 21.7 & $4.37 \mathrm{E}-01$ & 21.0 & $8.26 \mathrm{E}-03$ & 21.7 & $4.51 \mathrm{E}-01$ & 20.4 \\
\hline $\mathbf{X} \mathbf{e}^{\mathrm{d}}$ & & $17 \%$ & & & & $20 \%$ & & & \\
\hline${ }^{133} \mathrm{Cs}$ & $3.72 \mathrm{E}-01$ & $5.39 \mathrm{E}-02$ & 7.0 & $3.18 \mathrm{E}-01$ & 6.7 & $6.31 \mathrm{E}-02$ & 7.0 & 3.09E-01 & 6.9 \\
\hline $\mathbf{C s}^{\mathrm{d}}$ & & $15 \%$ & & & & $17 \%$ & & & \\
\hline
\end{tabular}


Table 2-Continued

\begin{tabular}{|c|c|c|c|c|c|c|c|c|c|}
\hline \multirow{2}{*}{ Nucleus } & \multirow{2}{*}{$\begin{array}{c}\text { SOlAR } \\
\text { ABUNDANCE }^{b}\end{array}$} & \multicolumn{4}{|c|}{ STELLAR MODEL $^{\mathrm{a}}$} & \multicolumn{4}{|c|}{ ClaAsSiCAL MODEL $^{a}$} \\
\hline & & $N_{s}^{\text {main }}$ & $\begin{array}{c}\delta N_{s}^{\text {main }} \\
(\%)\end{array}$ & $N_{r}$ & $\begin{array}{l}\delta N_{r} \\
(\%)\end{array}$ & $N_{s}^{\operatorname{main}}$ & $\begin{array}{c}\delta N_{s}^{\text {main }} \\
(\%)\end{array}$ & $N_{r}$ & $\begin{array}{l}\delta N_{r} \\
(\%)\end{array}$ \\
\hline${ }^{134} \mathrm{Ba}$ & $1.09 \mathrm{E}-01$ & $1.07 \mathrm{E}-01$ & 7.1 & & & $58 \%{ }^{\mathrm{e}}$ & 7.1 & & \\
\hline${ }^{135} \mathrm{Ba}$ & $2.96 \mathrm{E}-01$ & $7.75 \mathrm{E}-02$ & 7.1 & $2.19 \mathrm{E}-01$ & 8.9 & 8.05E-02 & 7.1 & $2.15 \mathrm{E}-01$ & 9.1 \\
\hline${ }^{136} \mathrm{Ba}$ & $3.53 \mathrm{E}-01$ & $0.25 \%{ }^{\mathrm{e}}$ & 7.2 & & & $37 \%$ & 7.2 & & \\
\hline${ }^{137} \mathrm{Ba}$ & $5.04 \mathrm{E}-01$ & $3.30 \mathrm{E}-01$ & 7.3 & $1.74 \mathrm{E}-01$ & 23.0 & 3.67E-01 & 7.3 & $1.37 \mathrm{E}-01$ & 30.4 \\
\hline${ }^{138} \mathrm{Ba}$ & $3.22 \mathrm{E}+00$ & $2.76 \mathrm{E}+00$ & 6.5 & $4.59 \mathrm{E}-01$ & 58.8 & $18 \%^{\mathrm{e}}$ & 6.5 & & \\
\hline $\mathbf{B a}^{\mathrm{d}}$ & & $81 \%$ & & & & $92 \%$ & & & \\
\hline${ }^{139} \mathrm{La}$ & $4.46 \mathrm{E}-01$ & $2.77 \mathrm{E}-01$ & 7.3 & $1.69 \mathrm{E}-01$ & 13.1 & $3.69 \mathrm{E}-01$ & 7.3 & $7.71 \mathrm{E}-02$ & 36.8 \\
\hline $\mathbf{L a}^{\mathrm{d}}$ & & $62 \%$ & & & & $83 \%$ & & & \\
\hline${ }^{140} \mathrm{Ce}$ & $1.00 \mathrm{E}+00$ & $8.36 \mathrm{E}-01$ & 4.0 & $1.69 \mathrm{E}-01$ & 22.3 & $9.68 \mathrm{E}-01$ & 4.0 & $3.66 \mathrm{E}-02$ & 100 \\
\hline${ }^{142} \mathrm{Ce}$ & $1.26 \mathrm{E}-01$ & $2.79 \mathrm{E}-02$ & 3.9 & $9.81 \mathrm{E}-02$ & 2.5 & $1.17 \mathrm{E}-02$ & 3.9 & $1.14 \mathrm{E}-01$ & 1.9 \\
\hline $\mathbf{C e}^{\mathrm{d}}$ & & $77 \%$ & & & & $87 \%$ & & & \\
\hline${ }^{141} \mathrm{Pr}$ & $1.67 \mathrm{E}-01$ & 8.13E-02 & 2.7 & 8.57E-02 & 5.3 & $9.33 \mathrm{E}-02$ & 2.7 & 7.37E-02 & 6.4 \\
\hline $\mathbf{P r}^{\mathrm{d}}$ & & $49 \%$ & & & & $56 \%$ & & & \\
\hline${ }^{142} \mathrm{Nd}$ & $2.25 \mathrm{E}-01$ & $2.08 \mathrm{E}-01$ & 2.4 & & & $12 \%{ }^{\mathrm{e}}$ & 2.4 & & \\
\hline${ }^{143} \mathrm{Nd}$ & $1.00 \mathrm{E}-01$ & $3.16 \mathrm{E}-02$ & 1.9 & $6.84 \mathrm{E}-02$ & 2.1 & $3.75 \mathrm{E}-02$ & 1.9 & $6.25 \mathrm{E}-02$ & 2.4 \\
\hline${ }^{144} \mathrm{Nd}$ & $1.97 \mathrm{E}-01$ & $1.00 \mathrm{E}-01$ & 2.2 & $9.68 \mathrm{E}-02$ & 3.5 & $1.08 \mathrm{E}-01$ & 2.2 & 8.93E-02 & 3.9 \\
\hline${ }^{145} \mathrm{Nd}$ & $6.87 \mathrm{E}-02$ & $1.89 \mathrm{E}-02$ & 1.7 & $4.98 \mathrm{E}-02$ & 1.9 & $2.20 \mathrm{E}-02$ & 1.7 & 4.67E-02 & 2.1 \\
\hline${ }^{146} \mathrm{Nd}$ & $1.42 \mathrm{E}-01$ & $9.11 \mathrm{E}-02$ & 1.7 & $5.09 \mathrm{E}-02$ & 4.7 & $9.12 \mathrm{E}-02$ & 1.7 & $5.08 \mathrm{E}-02$ & 4.7 \\
\hline${ }^{148} \mathrm{Nd}$ & $4.77 \mathrm{E}-02$ & $9.05 \mathrm{E}-03$ & 1.8 & $3.87 \mathrm{E}-02$ & 1.7 & $3.77 \mathrm{E}-03$ & 1.8 & 4.39E-02 & 1.4 \\
\hline $\mathbf{N d}^{\mathrm{d}}$ & & $56 \%$ & & & & $59 \%$ & & & \\
\hline${ }^{147} \mathrm{Sm}$ & $3.99 \mathrm{E}-02$ & $8.25 \mathrm{E}-03$ & 1.7 & $3.17 \mathrm{E}-02$ & 1.7 & 8.91E-03 & 1.7 & $3.10 \mathrm{E}-02$ & 1.7 \\
\hline${ }^{148} \mathrm{Sm}$ & $2.92 \mathrm{E}-02$ & $2.82 \mathrm{E}-02$ & 1.6 & & & $1.8 \%^{\mathrm{e}}$ & 1.6 & & \\
\hline${ }^{149} \mathrm{Sm}$ & $3.56 \mathrm{E}-02$ & $4.45 \mathrm{E}-03$ & 1.6 & $3.12 \mathrm{E}-02$ & 1.5 & $4.49 \mathrm{E}-03$ & 1.6 & $3.11 \mathrm{E}-02$ & 1.5 \\
\hline${ }^{150} \mathrm{Sm}$ & $1.91 \mathrm{E}-02$ & $1.91 \mathrm{E}-02$ & 1.6 & & & $1.91 \mathrm{E}-02$ & 1.6 & & \\
\hline${ }^{152} \mathrm{Sm}$ & $6.89 \mathrm{E}-02$ & $1.58 \mathrm{E}-02$ & 1.6 & $5.31 \mathrm{E}-02$ & 1.8 & $1.55 \mathrm{E}-02$ & 1.6 & $5.34 \mathrm{E}-02$ & 1.7 \\
\hline${ }^{154} \mathrm{Sm}$ & $5.86 \mathrm{E}-02$ & $4.69 \mathrm{E}-04$ & 6.6 & $5.81 \mathrm{E}-02$ & 1.3 & $3.18 \mathrm{E}-04$ & 6.6 & $5.83 \mathrm{E}-02$ & 1.3 \\
\hline $\mathbf{S m}^{\mathrm{d}}$ & & $29 \%$ & & & & $30 \%$ & & & \\
\hline${ }^{151} \mathrm{Eu}$ & $4.65 \mathrm{E}-02$ & $3.04 \mathrm{E}-03$ & 4.3 & $4.35 \mathrm{E}-02$ & 1.7 & $4.29 \mathrm{E}-03$ & 4.3 & $4.22 \mathrm{E}-02$ & 1.8 \\
\hline${ }^{153} \mathrm{Eu}$ & $5.08 \mathrm{E}-02$ & $2.58 \mathrm{E}-03$ & 10.1 & $4.82 \mathrm{E}-02$ & 1.8 & $3.04 \mathrm{E}-03$ & 10.1 & $4.78 \mathrm{E}-02$ & 1.8 \\
\hline $\mathbf{E u}^{\mathrm{d}}$ & & $5.8 \%$ & & & & $7.5 \%$ & & & \\
\hline
\end{tabular}


Table 2-Continued

\begin{tabular}{|c|c|c|c|c|c|c|c|c|c|}
\hline \multirow{2}{*}{ Nucleus } & \multirow{2}{*}{$\begin{array}{c}\text { Solar } \\
\text { ABUNDANCE }^{\mathrm{b}}\end{array}$} & \multicolumn{4}{|c|}{ STELLAR MODEL $^{\mathrm{a}}$} & \multicolumn{4}{|c|}{ ClLASSICAL MODEL $^{\mathrm{a}}$} \\
\hline & & $N_{s}^{\text {main }}$ & $\begin{array}{c}\delta N_{s}^{\text {main }} \\
(\%)\end{array}$ & $N_{r}$ & $\begin{array}{l}\delta N_{r} \\
(\%)\end{array}$ & $N_{s}^{\text {main }}$ & $\begin{array}{c}\delta N_{s}^{\text {main }} \\
(\%)\end{array}$ & $N_{r}$ & $\begin{array}{l}\delta N_{r} \\
(\%)\end{array}$ \\
\hline${ }^{152} \mathrm{Gd}^{\mathrm{g}}$ & $6.60 \mathrm{E}-04$ & $5.83 \mathrm{E}-04$ & 2.1 & & & $4.72 \mathrm{E}-04$ & 2.1 & & \\
\hline${ }^{154} \mathrm{Gd}$ & 7.19E-03 & $6.85 \mathrm{E}-03$ & 1.8 & & & $6.26 \mathrm{E}-03$ & 1.8 & & \\
\hline${ }^{155} \mathrm{Gd}$ & $4.88 \mathrm{E}-02$ & $2.88 \mathrm{E}-03$ & 1.8 & $4.59 \mathrm{E}-02$ & 1.5 & $3.50 \mathrm{E}-03$ & 1.8 & $4.53 \mathrm{E}-02$ & 1.5 \\
\hline${ }^{156} \mathrm{Gd}$ & $6.76 \mathrm{E}-02$ & $1.15 \mathrm{E}-02$ & 1.6 & $5.61 \mathrm{E}-02$ & 1.7 & $1.28 \mathrm{E}-02$ & 1.6 & $5.48 \mathrm{E}-02$ & 1.8 \\
\hline${ }^{157} \mathrm{Gd}$ & $5.16 \mathrm{E}-02$ & $5.53 \mathrm{E}-03$ & 1.8 & 4.61E-02 & 1.6 & $5.76 \mathrm{E}-03$ & 1.8 & $4.58 \mathrm{E}-02$ & 1.6 \\
\hline${ }^{158} \mathrm{Gd}$ & $8.20 \mathrm{E}-02$ & $2.25 \mathrm{E}-02$ & 1.6 & $5.95 \mathrm{E}-02$ & 2.0 & $2.40 \mathrm{E}-02$ & 1.6 & $5.80 \mathrm{E}-02$ & 2.1 \\
\hline${ }^{160} \mathrm{Gd}$ & 7.21E-02 & $8.27 \mathrm{E}-04$ & 9.7 & 7.13E-02 & 1.4 & $2.22 \mathrm{E}-05$ & 9.7 & $7.21 \mathrm{E}-02$ & 1.4 \\
\hline $\mathbf{G d}^{\mathrm{d}}$ & & $15 \%$ & & & & $16 \%$ & & & \\
\hline${ }^{159} \mathrm{~Tb}$ & $6.03 \mathrm{E}-02$ & $4.36 \mathrm{E}-03$ & 6.0 & $5.59 \mathrm{E}-02$ & 2.4 & $5.05 \mathrm{E}-03$ & 6.0 & $5.52 \mathrm{E}-02$ & 2.5 \\
\hline $\mathbf{T} \mathbf{b}^{\mathrm{d}}$ & & $7.2 \%$ & & & & $8.4 \%$ & & & \\
\hline${ }^{160} \mathrm{Dy}$ & $9.22 \mathrm{E}-03$ & $8.06 \mathrm{E}-03$ & 1.9 & & & $8.34 \mathrm{E}-03$ & 1.9 & & \\
\hline${ }^{161}$ Dy & $7.45 \mathrm{E}-02$ & $4.12 \mathrm{E}-03$ & 1.7 & 7.04E-02 & 1.5 & $3.88 \mathrm{E}-03$ & 1.7 & $7.06 \mathrm{E}-02$ & 1.5 \\
\hline${ }^{162}$ Dy & $1.01 \mathrm{E}-01$ & $1.64 \mathrm{E}-02$ & 1.6 & $8.46 \mathrm{E}-02$ & 1.7 & $1.66 \mathrm{E}-02$ & 1.6 & $8.44 \mathrm{E}-02$ & 1.7 \\
\hline${ }^{163}$ Dy & $9.82 \mathrm{E}-02$ & $3.52 \mathrm{E}-03$ & 2.0 & $9.47 \mathrm{E}-02$ & 1.5 & $4.85 \mathrm{E}-03$ & 2.0 & $9.34 \mathrm{E}-02$ & 1.5 \\
\hline${ }^{164}$ Dy & $1.11 \mathrm{E}-01$ & $2.61 \mathrm{E}-02$ & 1.9 & $8.49 \mathrm{E}-02$ & 1.9 & $1.57 \mathrm{E}-02$ & 1.9 & $9.53 \mathrm{E}-02$ & 1.7 \\
\hline Dy $^{\mathrm{d}}$ & & $15 \%$ & & & & $13 \%$ & & & \\
\hline${ }^{165} \mathrm{Ho}$ & 8.89E-02 & $6.95 \mathrm{E}-03$ & 5.6 & $8.20 \mathrm{E}-02$ & 2.6 & $5.82 \mathrm{E}-03$ & 5.6 & $8.31 \mathrm{E}-02$ & 2.6 \\
\hline $\mathbf{H o}^{\mathrm{d}}$ & & $7.8 \%$ & & & & $6.5 \%$ & & & \\
\hline${ }^{164} \mathrm{Er}$ & $4.04 \mathrm{E}-03$ & $3.34 \mathrm{E}-03$ & 4.9 & & & $3.49 \mathrm{E}-03$ & 4.9 & & \\
\hline${ }^{166} \mathrm{Er}$ & $8.43 \mathrm{E}-02$ & $1.25 \mathrm{E}-02$ & 10.1 & $7.18 \mathrm{E}-02$ & 2.3 & $1.34 \mathrm{E}-02$ & 10.1 & 7.09E-02 & 2.5 \\
\hline${ }^{167} \mathrm{Er}$ & $5.76 \mathrm{E}-02$ & 4.92E-03 & 10.1 & $5.27 \mathrm{E}-02$ & 1.7 & $5.23 \mathrm{E}-03$ & 10.1 & $5.24 \mathrm{E}-02$ & 1.7 \\
\hline${ }^{168} \mathrm{Er}$ & $6.72 \mathrm{E}-02$ & $1.90 \mathrm{E}-02$ & 12.1 & $4.82 \mathrm{E}-02$ & 5.1 & $2.17 \mathrm{E}-02$ & 12.1 & $4.55 \mathrm{E}-02$ & 6.1 \\
\hline${ }^{170} \mathrm{Er}$ & $3.74 \mathrm{E}-02$ & $2.69 \mathrm{E}-03$ & 14.9 & $3.47 \mathrm{E}-02$ & 1.8 & $2.19 \mathrm{E}-03$ & 14.9 & $3.52 \mathrm{E}-02$ & 1.7 \\
\hline $\mathbf{E r}^{\mathrm{d}}$ & & $17 \%$ & & & & $18 \%$ & & & \\
\hline${ }^{169} \mathrm{Tm}$ & $3.78 \mathrm{E}-02$ & $5.03 \mathrm{E}-03$ & 5.5 & $3.28 \mathrm{E}-02$ & 2.8 & $6.78 \mathrm{E}-03$ & 5.5 & $3.10 \mathrm{E}-02$ & 3.0 \\
\hline $\mathbf{T} \mathbf{m}^{\mathrm{d}}$ & & $13 \%$ & & & & $18 \%$ & & & \\
\hline
\end{tabular}


Table 2-Continued

\begin{tabular}{|c|c|c|c|c|c|c|c|c|c|}
\hline \multirow{2}{*}{ Nucleus } & \multirow{2}{*}{$\begin{array}{c}\text { SOLAR } \\
\text { ABUNDANCE }^{\mathrm{b}}\end{array}$} & \multicolumn{4}{|c|}{ STELLAR MODEL ${ }^{\mathrm{a}}$} & \multicolumn{4}{|c|}{ ClASSICAL MODEL $^{\mathrm{a}}$} \\
\hline & & $N_{s}^{\text {main }}$ & $\begin{array}{c}\delta N_{s}^{\text {main }} \\
(\%)\end{array}$ & $N_{r}$ & $\begin{array}{l}\delta N_{r} \\
(\%)\end{array}$ & $N_{s}^{\text {main }}$ & $\begin{array}{c}\delta N_{s}^{\operatorname{main}} \\
(\%)\end{array}$ & $N_{r}$ & $\begin{array}{l}\delta N_{r} \\
(\%)\end{array}$ \\
\hline${ }^{170} \mathrm{Yb}$ & $7.56 \mathrm{E}-03$ & $1.1 \% \mathrm{o}^{\mathrm{e}}$ & 4.2 & & & $6.56 \mathrm{E}-03$ & 4.2 & & \\
\hline${ }^{171} \mathrm{Yb}$ & $3.54 \mathrm{E}-02$ & $4.93 \mathrm{E}-03$ & 3.9 & 3.05E-02 & 2.0 & $6.07 \mathrm{E}-03$ & 3.9 & $2.93 \mathrm{E}-02$ & 2.1 \\
\hline${ }^{172} \mathrm{Yb}$ & $5.43 \mathrm{E}-02$ & $1.65 \mathrm{E}-02$ & 8.4 & $3.78 \mathrm{E}-02$ & 4.3 & $1.77 \mathrm{E}-02$ & 8.4 & $3.66 \mathrm{E}-02$ & 4.7 \\
\hline${ }^{173} \mathrm{Yb}$ & $4.00 \mathrm{E}-02$ & 8.57E-03 & 8.5 & $3.14 \mathrm{E}-02$ & 3.1 & $8.92 \mathrm{E}-03$ & 8.5 & 3.11E-02 & 3.2 \\
\hline${ }^{174} \mathrm{Yb}$ & $7.88 \mathrm{E}-02$ & $3.91 \mathrm{E}-02$ & 9.2 & $3.97 \mathrm{E}-02$ & 9.6 & $4.27 \mathrm{E}-02$ & 9.2 & $3.61 \mathrm{E}-02$ & 11.5 \\
\hline${ }^{176} \mathrm{Yb}$ & $3.15 \mathrm{E}-02$ & $4.28 \mathrm{E}-03$ & 10.0 & $2.72 \mathrm{E}-02$ & 2.4 & $1.10 \mathrm{E}-03$ & 10.0 & $3.04 \mathrm{E}-02$ & 1.7 \\
\hline $\mathbf{Y b}^{\mathrm{d}}$ & & $33 \%$ & & & & $34 \%$ & & & \\
\hline${ }^{175} \mathrm{Lu}$ & $3.57 \mathrm{E}-02$ & $6.33 \mathrm{E}-03$ & 4.0 & $2.94 \mathrm{E}-02$ & 1.8 & $5.91 \mathrm{E}-03$ & 4.0 & $2.98 \mathrm{E}-02$ & 1.7 \\
\hline${ }^{176} \mathrm{Lu}$ & $1.03 \mathrm{E}-03$ & $25 \%^{\mathrm{e}}$ & 4.1 & & & $83 \% \mathrm{e}^{\mathrm{e}}$ & 4.1 & & \\
\hline $\mathbf{L} \mathbf{u}^{\mathrm{d}}$ & & $20 \%$ & & & & $19 \%$ & & & \\
\hline${ }^{176} \mathrm{Hf}$ & 7.93E-03 & $7.65 \mathrm{E}-03$ & 4.8 & & & $6.9 \%^{\mathrm{e}}$ & 4.8 & & \\
\hline${ }^{177} \mathrm{Hf}$ & $2.87 \mathrm{E}-02$ & $5.29 \mathrm{E}-03$ & 4.9 & $2.34 \mathrm{E}-02$ & 2.6 & $5.14 \mathrm{E}-03$ & 4.9 & $2.36 \mathrm{E}-02$ & 2.5 \\
\hline${ }^{178} \mathrm{Hf}$ & $4.20 \mathrm{E}-02$ & $2.40 \mathrm{E}-02$ & 3.7 & $1.80 \mathrm{E}-02$ & 6.7 & $2.19 \mathrm{E}-02$ & 3.7 & $2.01 \mathrm{E}-02$ & 5.7 \\
\hline${ }^{179} \mathrm{Hf}$ & $2.10 \mathrm{E}-02$ & $7.74 \mathrm{E}-03$ & 3.6 & $1.33 \mathrm{E}-02$ & 3.7 & $6.80 \mathrm{E}-03$ & 3.6 & $1.42 \mathrm{E}-02$ & 3.3 \\
\hline${ }^{180} \mathrm{Hf}$ & $5.41 \mathrm{E}-02$ & $4.08 \mathrm{E}-02$ & 3.4 & $1.33 \mathrm{E}-02$ & 13.1 & $3.71 \mathrm{E}-02$ & 3.4 & $1.70 \mathrm{E}-02$ & 9.6 \\
\hline $\mathbf{H f}^{\mathrm{d}}$ & & $56 \%$ & & & & $51 \%$ & & & \\
\hline${ }^{180} \mathrm{Ta}$ & $2.48 \mathrm{E}-06$ & $1.21 \mathrm{E}-06$ & 20.1 & & & $17 \%^{\mathrm{e}}$ & 20.1 & & \\
\hline${ }^{181} \mathrm{Ta}$ & $2.07 \mathrm{E}-02$ & $8.55 \mathrm{E}-03$ & 2.7 & $1.22 \mathrm{E}-02$ & 3.6 & $8.53 \mathrm{E}-03$ & 2.7 & $1.22 \mathrm{E}-02$ & 3.6 \\
\hline $\mathbf{T a}^{\mathrm{d}}$ & & $41 \%$ & & & & $41 \%$ & & & \\
\hline${ }^{180} \mathrm{~W}$ & $1.73 \mathrm{E}-04$ & $8.02 \mathrm{E}-06$ & 11.6 & & & $1.38 \mathrm{E}-04$ & 11.6 & & \\
\hline${ }^{182} \mathrm{~W}$ & $3.50 \mathrm{E}-02$ & $1.60 \mathrm{E}-02$ & 7.2 & $1.90 \mathrm{E}-02$ & 11.2 & $1.35 \mathrm{E}-02$ & 7.2 & $2.15 \mathrm{E}-02$ & 9.5 \\
\hline${ }^{183} \mathrm{~W}$ & $1.90 \mathrm{E}-02$ & $1.02 \mathrm{E}-02$ & 7.2 & $8.76 \mathrm{E}-03$ & 13.9 & $1.24 \mathrm{E}-02$ & 7.2 & $6.64 \mathrm{E}-03$ & 19.8 \\
\hline${ }^{184} \mathrm{~W}$ & $4.08 \mathrm{E}-02$ & $2.88 \mathrm{E}-02$ & 7.3 & $1.20 \mathrm{E}-02$ & 24.5 & $2.82 \mathrm{E}-02$ & 7.3 & $1.26 \mathrm{E}-02$ & 23.2 \\
\hline${ }^{186} \mathrm{~W}$ & $3.80 \mathrm{E}-02$ & $1.91 \mathrm{E}-02$ & 7.0 & $1.89 \mathrm{E}-02$ & 12.5 & $8.41 \mathrm{E}-03$ & 7.0 & $2.96 \mathrm{E}-02$ & 6.8 \\
\hline $\mathbf{W}^{\mathrm{d}}$ & & $56 \%$ & & & & $47 \%$ & & & \\
\hline${ }^{185} \mathrm{Re}$ & $1.93 \mathrm{E}-02$ & $4.78 \mathrm{E}-03$ & 10.2 & $1.45 \mathrm{E}-02$ & 12.9 & $5.91 \mathrm{E}-03$ & 10.2 & $1.34 \mathrm{E}-02$ & 14.3 \\
\hline${ }^{187} \mathrm{Re}$ & $3.51 \mathrm{E}-02$ & $6.65 \mathrm{E}-05$ & 10.6 & $3.50 \mathrm{E}-02$ & 9.4 & $1.55 \mathrm{E}-03$ & 10.6 & $3.36 \mathrm{E}-02$ & 9.8 \\
\hline $\operatorname{Re}^{\mathrm{d}}$ & & $8.9 \%$ & & & & $14 \%$ & & & \\
\hline
\end{tabular}


Table 2-Continued

\begin{tabular}{|c|c|c|c|c|c|c|c|c|c|}
\hline \multirow{2}{*}{ Nucleus } & \multirow{2}{*}{$\begin{array}{c}\text { SOLAR } \\
\text { ABUNDANCE }^{\mathrm{b}}\end{array}$} & \multicolumn{4}{|c|}{ STELLAR MODEL $^{\mathrm{a}}$} & \multicolumn{4}{|c|}{ 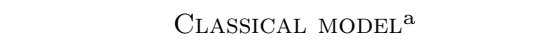 } \\
\hline & & $N_{s}^{\text {main }}$ & $\begin{array}{c}\delta N_{s}^{\text {main }} \\
(\%)\end{array}$ & $N_{r}$ & $\begin{array}{l}\delta N_{r} \\
(\%)\end{array}$ & $N_{s}^{\text {main }}$ & $\begin{array}{c}\delta N_{s}^{\text {main }} \\
(\%)\end{array}$ & $N_{r}$ & $\begin{array}{l}\delta N_{r} \\
(\%)\end{array}$ \\
\hline${ }^{186} \mathrm{Os}$ & $1.07 \mathrm{E}-02$ & $1.04 \mathrm{E}-02$ & 7.4 & & & $1.06 \mathrm{E}-02$ & 7.4 & & \\
\hline${ }^{187} \mathrm{Os}$ & 8.07E-03 & $6.58 \mathrm{E}-03$ & 7.1 & & & $4.99 \mathrm{E}-03$ & 7.1 & & \\
\hline${ }^{188} \mathrm{Os}$ & $8.98 \mathrm{E}-02$ & $1.72 \mathrm{E}-02$ & 7.3 & $7.26 \mathrm{E}-02$ & 8.0 & $1.54 \mathrm{E}-02$ & 7.3 & $7.44 \mathrm{E}-02$ & 7.7 \\
\hline${ }^{189} \mathrm{Os}$ & $1.09 \mathrm{E}-01$ & $4.70 \mathrm{E}-03$ & 7.5 & $1.04 \mathrm{E}-01$ & 6.6 & $5.25 \mathrm{E}-03$ & 7.5 & $1.04 \mathrm{E}-01$ & 6.6 \\
\hline${ }^{190} \mathrm{Os}$ & $1.78 \mathrm{E}-01$ & $2.14 \mathrm{E}-02$ & 16.5 & $1.57 \mathrm{E}-01$ & 7.5 & $2.04 \mathrm{E}-02$ & 16.5 & $1.58 \mathrm{E}-01$ & 7.4 \\
\hline${ }^{192} \mathrm{Os}$ & $2.77 \mathrm{E}-01$ & $2.86 \mathrm{E}-03$ & 15.8 & $2.74 \mathrm{E}-01$ & 6.4 & $1.03 \mathrm{E}-03$ & 15.8 & $2.76 \mathrm{E}-01$ & 6.3 \\
\hline $\mathrm{Os}^{\mathrm{d}}$ & & $9.4 \%$ & & & & $8.6 \%$ & & & \\
\hline${ }^{191} \mathrm{Ir}$ & $2.47 \mathrm{E}-01$ & $4.68 \mathrm{E}-03$ & 7.9 & $2.42 \mathrm{E}-01$ & 6.2 & $4.57 \mathrm{E}-03$ & 7.9 & $2.42 \mathrm{E}-01$ & 6.2 \\
\hline${ }^{193} \mathrm{Ir}$ & $4.14 \mathrm{E}-01$ & $4.40 \mathrm{E}-03$ & 7.9 & 4.10E-01 & 6.2 & $6.13 \mathrm{E}-03$ & 7.9 & $4.08 \mathrm{E}-01$ & 6.2 \\
\hline $\mathbf{I r}^{\mathrm{d}}$ & & $1.4 \%$ & & & & $1.6 \%$ & & & \\
\hline${ }^{192} \mathrm{Pt}$ & $1.05 \mathrm{E}-02$ & $1.03 \mathrm{E}-02$ & 50.5 & & & $51 \%{ }^{\mathrm{e}}$ & 50.5 & & \\
\hline${ }^{194} \mathrm{Pt}$ & $4.41 \mathrm{E}-01$ & $1.77 \mathrm{E}-02$ & 50.5 & $4.23 \mathrm{E}-01$ & 8.0 & $1.87 \mathrm{E}-02$ & 50.5 & $4.22 \mathrm{E}-01$ & 8.0 \\
\hline${ }^{195} \mathrm{Pt}$ & $4.53 \mathrm{E}-01$ & $7.53 \mathrm{E}-03$ & 50.5 & $4.45 \mathrm{E}-01$ & 7.6 & $5.58 \mathrm{E}-03$ & 50.5 & $4.47 \mathrm{E}-01$ & 7.5 \\
\hline${ }^{196} \mathrm{Pt}$ & 3.38E-01 & $3.30 \mathrm{E}-02$ & 13.8 & 3.05E-01 & 8.3 & 2.95E-02 & 13.8 & 3.09E-01 & 8.2 \\
\hline${ }^{198} \mathrm{Pt}$ & $9.63 \mathrm{E}-02$ & $2.33 \mathrm{E}-05$ & 12.1 & $9.63 \mathrm{E}-02$ & 7.4 & $5.98 \mathrm{E}-05$ & 12.1 & $9.62 \mathrm{E}-02$ & 7.4 \\
\hline $\mathbf{P t}^{\mathrm{d}}$ & & $5.1 \%$ & & & & $4.8 \%$ & & & \\
\hline${ }^{197} \mathrm{Au}$ & $1.87 \mathrm{E}-01$ & $1.09 \mathrm{E}-02$ & 15.1 & $1.76 \mathrm{E}-01$ & 16.0 & $9.72 \mathrm{E}-03$ & 15.1 & $1.77 \mathrm{E}-01$ & 15.8 \\
\hline $\mathbf{A} \mathbf{u}^{\mathrm{d}}$ & & $5.8 \%$ & & & & $5.2 \%$ & & & \\
\hline${ }^{198} \mathrm{Hg}$ & $3.39 \mathrm{E}-02$ & $2.4 \%^{\mathrm{e}}$ & 14.8 & & & $3.12 \mathrm{E}-02$ & 14.8 & & \\
\hline${ }^{199} \mathrm{Hg}$ & $5.74 \mathrm{E}-02$ & $1.52 \mathrm{E}-02$ & 13.5 & $4.22 \mathrm{E}-02$ & 17.0 & $1.44 \mathrm{E}-02$ & 13.5 & $4.30 \mathrm{E}-02$ & 16.6 \\
\hline${ }^{200} \mathrm{Hg}$ & 7.85E-02 & $5.15 \mathrm{E}-02$ & 15.9 & $2.70 \mathrm{E}-02$ & 46.3 & $4.50 \mathrm{E}-02$ & 15.9 & $3.35 \mathrm{E}-02$ & 35.3 \\
\hline${ }^{201} \mathrm{Hg}$ & $4.48 \mathrm{E}-02$ & $2.22 \mathrm{E}-02$ & 13.1 & $2.26 \mathrm{E}-02$ & 27.1 & $1.93 \mathrm{E}-02$ & 13.1 & $2.55 \mathrm{E}-02$ & 23.3 \\
\hline${ }^{202} \mathrm{Hg}$ & $1.02 \mathrm{E}-01$ & $8.23 \mathrm{E}-02$ & 14.5 & $1.92 \mathrm{E}-02$ & 88.6 & $6.44 \mathrm{E}-02$ & 14.5 & $3.71 \mathrm{E}-02$ & 41.4 \\
\hline${ }^{204} \mathrm{Hg}$ & $2.33 \mathrm{E}-02$ & $2.07 \mathrm{E}-03$ & 15.3 & $2.12 \mathrm{E}-02$ & 13.3 & $3.51 \mathrm{E}-04$ & 15.3 & $2.29 \mathrm{E}-02$ & 12.2 \\
\hline $\mathbf{H g}^{\mathrm{d}}$ & & $61 \%$ & & & & $51 \%$ & & & \\
\hline${ }^{203} \mathrm{Tl}$ & $5.43 \mathrm{E}-02$ & $4.06 \mathrm{E}-02$ & 11.4 & $1.37 \mathrm{E}-02$ & 50.3 & $3.70 \mathrm{E}-02$ & 11.4 & $1.73 \mathrm{E}-02$ & 38.3 \\
\hline${ }^{205} \mathrm{Tl}$ & $1.30 \mathrm{E}-01$ & $9.89 \mathrm{E}-02$ & 12.0 & $3.08 \mathrm{E}-02$ & 55.1 & $7.61 \mathrm{E}-02$ & 12.0 & $5.36 \mathrm{E}-02$ & 28.4 \\
\hline $\mathbf{T l}^{\mathrm{d}}$ & & $76 \%$ & & & & $61 \%$ & & & \\
\hline
\end{tabular}


Table 2-Continued

\begin{tabular}{|c|c|c|c|c|c|c|c|c|c|}
\hline \multirow{2}{*}{ NuCleus } & \multirow{2}{*}{$\begin{array}{c}\text { SOLAR } \\
\text { ABUNDANCE }\end{array}$} & \multicolumn{4}{|c|}{ STELLAR MODEL $^{\mathrm{a}}$} & \multicolumn{4}{|c|}{ Cllassical model $^{\mathrm{a}}$} \\
\hline & & $N_{s}^{\text {main }}$ & $\begin{array}{c}\delta N_{s}^{\operatorname{main}} \\
(\%)\end{array}$ & $N_{r}$ & $\begin{array}{l}\delta N_{r} \\
(\%)\end{array}$ & $N_{s}^{\operatorname{main}}$ & $\begin{array}{c}\delta N_{s}^{\operatorname{main}} \\
(\%)\end{array}$ & $N_{r}$ & $\begin{array}{l}\delta N_{r} \\
(\%)\end{array}$ \\
\hline${ }^{204} \mathrm{~Pb}$ & $6.11 \mathrm{E}-02$ & $5.76 \mathrm{E}-02$ & 9.9 & & & 4.83E-02 & 9.9 & & \\
\hline${ }^{206} \mathrm{~Pb}^{\mathrm{f}}$ & $5.93 \mathrm{E}-01$ & $3.43 \mathrm{E}-01$ & 10.6 & & & $1.84 \mathrm{E}-01$ & 10.6 & & \\
\hline${ }^{207} \mathrm{~Pb}^{\mathrm{f}}$ & $6.44 \mathrm{E}-01$ & $4.10 \mathrm{E}-01$ & 9.4 & & & $1.90 \mathrm{E}-01$ & 9.4 & & \\
\hline${ }^{208} \mathrm{~Pb}^{\mathrm{f}}$ & $1.83 \mathrm{E}+00$ & $6.30 \mathrm{E}-01$ & 8.4 & & & $1.81 \mathrm{E}-01$ & 8.4 & & \\
\hline $\mathbf{P b}^{\mathrm{d}}$ & & $46 \%$ & & & & $19 \%$ & & & \\
\hline${ }^{209} \mathrm{Bi}^{\mathrm{f}}$ & $1.44 \mathrm{E}-01$ & 7.07E-03 & 13.1 & $1.37 \mathrm{E}-01$ & 8.6 & $4.88 \mathrm{E}-03$ & 13.1 & $1.39 \mathrm{E}-01$ & 8.5 \\
\hline $\mathbf{B i}^{\mathrm{d}}$ & & $4.9 \%$ & & & & $3.4 \%$ & & & \\
\hline
\end{tabular}

${ }^{a}$ The abundance distributions are normalized to ${ }^{150} \mathrm{Sm}$.

${ }^{\mathrm{b}}$ Anders, \& Grevesse (1989)

${ }^{\mathrm{c}}$ Between $\mathrm{Cu}$ and $\mathrm{Sr}$ the contribution of the weak $s$ component has been considered via the single exposure calculation of Beer, Walter, \& Käppeler (1992). In this region the $\delta N_{r}$ uncertainties are omitted, since this modification is beyond the scope of the present paper.

dThe final line for each element denotes the contribution in percent of the main $s$ component to the solar elemental abundance.

ePercent values in boldface denote an overabundance with respect to solar.

${ }^{\mathrm{f}}$ An important contribution from low metallicity stars is to be expected according to Gallino et al. (1998).

g A contribution of $\sim 6 \%$ from the weak $s$-component is to be expected (Raiteri et al. 1993). 


\section{REFERENCES}

Anders, E., \& Grevesse, N. 1989, Geochim. Cosmochim. Acta, 53, 197

Arlandini, C., Gallino, R., Busso, M., \& Straniero, O. 1995, in Stellar Evolution: what should be done, ed. A. Noels, D. Fraipont-Caro, M. Gabriel, N. Grevesse, \& P. Demarque (Liège: Univ. de Liège), 447

Arlandini, C., Käppeler, F., \& Wisshak, K. 1998, Verhandl. DPG , 33, 456

Auble, R. 1983, Nucl. Data Sheets, 40, 301

Bao, Z. Y., \& Käppeler, F. 1987, Atom. Data Nucl. Data Tables, 36, 411

Beer, H. 1991, ApJ, 379, 409

Beer, H., Corvi, F., \& Mutti, P. 1997, ApJ, 474, 843

Beer, H., \& Käppeler, F. 1980, Phys. Rev. C, 21, 534

Beer, H., \& Macklin, R. L. 1989, ApJ, 339, 962

Beer, H., Voss, F., \& Winters, R. R. 1992, ApJS, 80, 403

Beer, H., Walter, G., \& Käppeler, F. 1992, ApJ, 389, 784

Best, J. 1996, Forschungszentrum Karlsruhe Scientific Reports, FZKA 5824 (unpublished)

Busso, M., Gallino, R., Lambert, D. L., Raiteri, C. M., \& Smith, V.V. 1992, ApJ, 399, 218

Busso, M., Gallino, R., \& Wasserburg, G. J. 1999, ARA\&A, in press

Busso, M., Lambert, D. L., Gallino, R., Beglio, L., Raiteri, C. M., \& Smith, V. V. 1995, ApJ, 446, 775

Busso, M., Picchio, G., Gallino, R., \& Chieffi, A. 1988, ApJ, 326, 196 
Busso, M., Travaglio, C., Gallino, R., Lugaro, M., \& Arlandini, C. 1999, in Nuclei in the Cosmos V, ed. N. Prantzos, \& S. Harissopulos (Paris: Editions Frontières), 227

Chieffi, A., Limongi, M., \& Straniero, O. 1998, ApJ, 478, 332

Chieffi, A., \& Straniero, O. 1989, ApJS, 71, 47

Clayton, D. D. 1968, Principles of Stellar Evolution and Nucleosynthesis (McGraw-Hill: New York)

Clayton, D. D., Fowler, W. A., Hull, T. E., \& Zimmermann, B. A. 1961, Ann. Phys., 12, 331

Clayton, D. D., \& Rassbach, M. E. 1967, ApJ, 148, 69

Clayton, D. D., \& Ward, R. A. 1974, ApJ, 193, 397

Cosner, K., Iben, I., Jr., \& Truran, J. W. 1980, ApJ, 238, L91

Cowan, J. J., Cameron, A. G. W., \& Truran, J. W. 1980, ApJ, 241, 1090

De Laeter, J. R., Rosman, K. J. R., \& Ly, C. 1998, Meteoritics \& Planet. Sci. Suppl., 33, A40

Denker, A., Drotleff, H. W., Große, M., Knee, H., Kunz, R., Mayer, A., Seidel, R., Soiné, M., Wöhr, A., Wolf, G., \& Hammer, J. W. 1995, in Nuclei in the Cosmos III, ed. M. Busso, R. Gallino, \& C. M. Raiteri (New York: American Institute of Physics Press), 255

Doll, C., Börner, H. G., Jaag, S., Kppeler, F., \& Andrejtscheff W. 1999, Phys. Rev. C, 59, 492

Frost, C. A., \& Lattanzio, J. L. 1996, ApJ, 473, 383 
Frost, C. A., \& Lattanzio, J. L. 1998, ApJ, 500, 355

Gallino, R., Arlandini, C., Busso, M., Lugaro, M., Travaglio, C., Straniero, O., Chieffi, A., \& Limongi, M. 1998, ApJ, 497, 388

Gallino, R., Busso, M., \& Lugaro, M. 1997, in Astrophysical Implications of the Laboratory Study of Presolar Materials, ed. T. Bernatowicz \& E. Zinner, (Woodbury: American Institute of Physics Press), 115

Gallino, R., Busso, M., Lugaro, M., Travaglio, C., Arlandini, C., \& Vaglio, P. 1999, in Nuclei in the Cosmos V, ed. N. Prantzos, \& S. Harissopulos (Paris: Editions Frontières), 216

Gallino, R., Busso, M., Picchio, G., Raiteri, C. M., \& Renzini, A. 1988, ApJ, 334, L45

Goriely, S. 1997, A\&A, 327, 845

Guber, K. H., Spencer, R. R., Koehler, P. E., \& Winters, R. R. 1997, Phys. Rev. Lett., 78, 2704

Harris, M. J. 1981, Ap\&SS, 77, 357

Hollowell, D. E., \& Iben, I., Jr. 1988, ApJ, 333, L25

Holmes, J. A., Woosley, S. E., Fowler, W. A., \& Zimmerman, B. A. 1976, Atom. Data Nucl. Data Tables, 18, 305

Howard, W. M. 1991, private communication

Howard, W. M., Meyer, B. S., \& Woosley, S. E. 1991, ApJ, 373, L5

Jaag, S. 1990, Master Thesis, Univ. of Karlsruhe

Jaag, S., \& Käppeler, F. 1996, ApJ, 464, 874 
Jaag, S., Stoll, H., Wisshak, K., Käppeler, F., Reffo, G., \& Rauscher, T. , Phys. Rev. C, in preparation

Jung, M., et al. 1992, Phys. Rev. Lett., 69, 2164

Käppeler, F., Beer, H., \& Wisshak, K. 1989, Rept. Progr. Phys., 52, 945

Käppeler, F., Beer, H., Wisshak, K., Clayton, D. D., Macklin, R. L., \& Ward, R. A. 1982, ApJ, 257, 821

Käppeler, F., Gallino, R., Busso, M., Picchio, G., \& Raiteri, C.M. 1990, ApJ, 354, 630

Käppeler, F., Toukan, K. A., Schumann, M., \& Mengoni, A. 1996, Phys. Rev. C, 53, 1397

Käppeler, F., Wiescher, M., Giesen, U., Görres, J., Baraffe, I., El Eid, M., Raiteri, C. M., Busso, M., Gallino, R., Limongi, M., \& Chieffi, A. 1994, ApJ, 437, 396

Lambert, D. L. 1995, private communication

Lambert, D. L., Smith, V. V., Busso, M., Gallino, R., \& Straniero, O. 1995, ApJ, 450, 302

Prantzos, N., Hashimoto, M., Rayet, M., \& Arnould, M. 1990, A\&A, 238, 455

Raiteri, C. M., Gallino, R., Busso, M., Neuberger, D., \& Käppeler, F. 1993, ApJ, 419, 207

Raiteri, C. M., Villata, M., Gallino, R., Busso, M., \& Cravanzola, A. 1999, ApJ, 518, L91

Ratynski, W., \& Käppeler, F. 1988, Phys. Rev. C, 37, 595

Rayet, M. 1991, private communication

Rayet, M., Arnould, M., Hashimoto, M., Prantzos, N., \& Nomoto, K. 1995, A\&A, 298, 517

Rayet, M., Prantzos, N., \& Arnould, M. 1990, A\&A, 227, 271

Schumann, M., Käppeler, F., Böttger, R., \& Schölermann H. 1998, Phys. Rev. C, 58, 1790 
Seeger, P. A., Fowler, W. A., \& Clayton, D. D. 1965, ApJS, 11, 121

Smith, V. V., \& Lambert, D. L. 1985, ApJ, 294, 326

Smith, V. V., \& Lambert, D. L. 1986, ApJ, 311, 843

Smith, V. V., \& Lambert, D. L. 1990, ApJS, 72, 387

Straniero, O., Chieffi, A., Limongi, M., Busso, M., Gallino, R., \& Arlandini, C. 1997, ApJ, 478,332

Straniero, O., Gallino, R., Busso, M., Chieffi, A., Raiteri, C. M., Salaris, M., \& Limongi, M. 1995, ApJ, 440, L85

Takahashi, K., \& Yokoi, K. 1987, Atom. Data Nucl. Data Tables, 36, 375

Toukan, K. A., Debus, K., Käppeler, F., \& Reffo, G. 1995, Phys. Rev. C, 51, 1540

Travaglio, C., Galli, D., Gallino, R., Busso, M., Ferrini, F., \& Straniero, O. 1999, ApJ, in press

Truran, J. W., \& Iben, I., Jr. 1977, ApJ, 216, 797

Ulrich, R. K. 1973, in Explosive Nucleosynthesis, ed. D. N. Schramm \& W. D. Arnett (Austin: University of Texas Press), 139

Vaglio, P., Gallino, R., Busso, M., Travaglio, C., Straniero, O., Chieffi, A., Limongi, M., Lugaro, M., \& Arlandini, C. 1999, in Nuclei in the Cosmos V, ed. N. Prantzos, \& S. Harissopulos (Paris: Editions Frontières), 223

Voss, F., Wisshak, K., Arlandini, C., Käppeler, F., Kazakov, L., \& Rauscher, T. 1999, Phys. Rev. C, 59, 1154

Voss, F., Wisshak, K., Guber, K., Käppeler, F., \& Reffo, G. 1994, Phys. Rev. C, 50, 2582 
Ward, R. A., \& Newman, M. J. 1978, ApJ, 219, 195

Ward, R. A., Newman, M. J., \& Clayton, D. D, 1976, ApJS, 31, 33

Wisshak, K., Guber, K., Käppeler, F., Krisch, J., Müller, H., Rupp, G. \& Voss, F. 1990, Nucl. Instr. Meth. A, 292, 595

Wisshak, K., Guber, K., Voss, F., Käppeler, F., \& Reffo, G. 1993, Phys. Rev. C, 48, 1401

Wisshak, K., Voss, F., \& Käppeler, F. 1998, Phys. Rev. C, 57, 3452

Wisshak, K., Voss, F., Käppeler, F., Guber, K., Kazakov, L., Kornilov, N., Uhl, M., \& Reffo, G. 1993, Phys. Rev. C, 52, 2762

Wisshak, K., Voss, F., Käppeler, F., Kazakov, L., \& Reffo, G. 1998, Phys. Rev. C, 57, 391

Wisshak, K., Voss, F., Theis, C., Käppeler, F., Guber, K., Kazakov, L., Kornilov, N., \& Reffo, G. 1996, Phys. Rev. C, 54, 1541 
Fig. 1. - The $s$-process reaction path in the Ce to $\mathrm{Nd}$ region, showing the branchings at $A$ $=141$ and 142 that cause part of the reaction flow to partly bypass ${ }^{142} \mathrm{Nd}$.

Fig. 2.- The $s$-process overproduction in the $120<A<160$ region obtained with the classical approach (left panels) and with the $2 M_{\odot}$ "standard" model at $Z=1 / 2 Z_{\odot}$ (right panels). The values are normalized to ${ }^{150} \mathrm{Sm}$. The top panels represent the results with the old Nd isotopes neutron capture cross sections, while the effect of the new data is plotted in the bottom panels. The uncertainties on both solar abundances and cross sections are taken into account.

Fig. 3.- The $s$-process abundance distribution that best reproduces the solar sistem main $s$ component, as obtained by the stellar model for a $1.5 M_{\odot}$ of $Z=1 / 2 Z_{\odot}$ ("standard model") with updated Nd cross sections. The abundances are plotted as overproduction factors with respect to the solar values, normalized to ${ }^{150} \mathrm{Sm}$. Circles indicate $s$-only nuclei. The uncertainties on both solar abundances and cross sections are taken into account.

Fig. 4.- The evolution of neutron density (top panel, right scale) and of the abundances, plotted as fractions of mass, of some relevant isotopes during the ${ }^{142} \mathrm{Nd}$ neutron release, for a typical advanced pulse (pulse 15 of the standard AGB model). The time scale starts at the moment of bottom temperature reaching $2.5 \times 10^{8} \mathrm{~K}$. The effective neutron density, as derived from the classical approach, is sketched in the top panel by a shaded band. In the top panel is plotted the evolution of the ${ }^{142} \mathrm{Nd}$ abundance, while the same for ${ }^{148} \mathrm{Sm}$ and ${ }^{150} \mathrm{Sm}$ is found in the middle panel, as for ${ }^{152} \mathrm{Gd}$ and ${ }^{154} \mathrm{Gd}$ in the bottom panel. The arrows indicate the freeze-out instants, as indicate by the criterion $X_{\text {freeze }}=0.9 X_{\text {final }}$.

Fig. 5. - The $r$-process residuals obtained by subtraction of the $s$-abundances obtained for the classical and for the stellar model. In this case, as a somewhat closer representation of the Galactic chemical evolution mechanism, an average of the distributions best reproducing 
the main component for the standard 1.5 and $3 M_{\odot}$ models at $Z=1 / 2 Z_{\odot}$ is considered. 


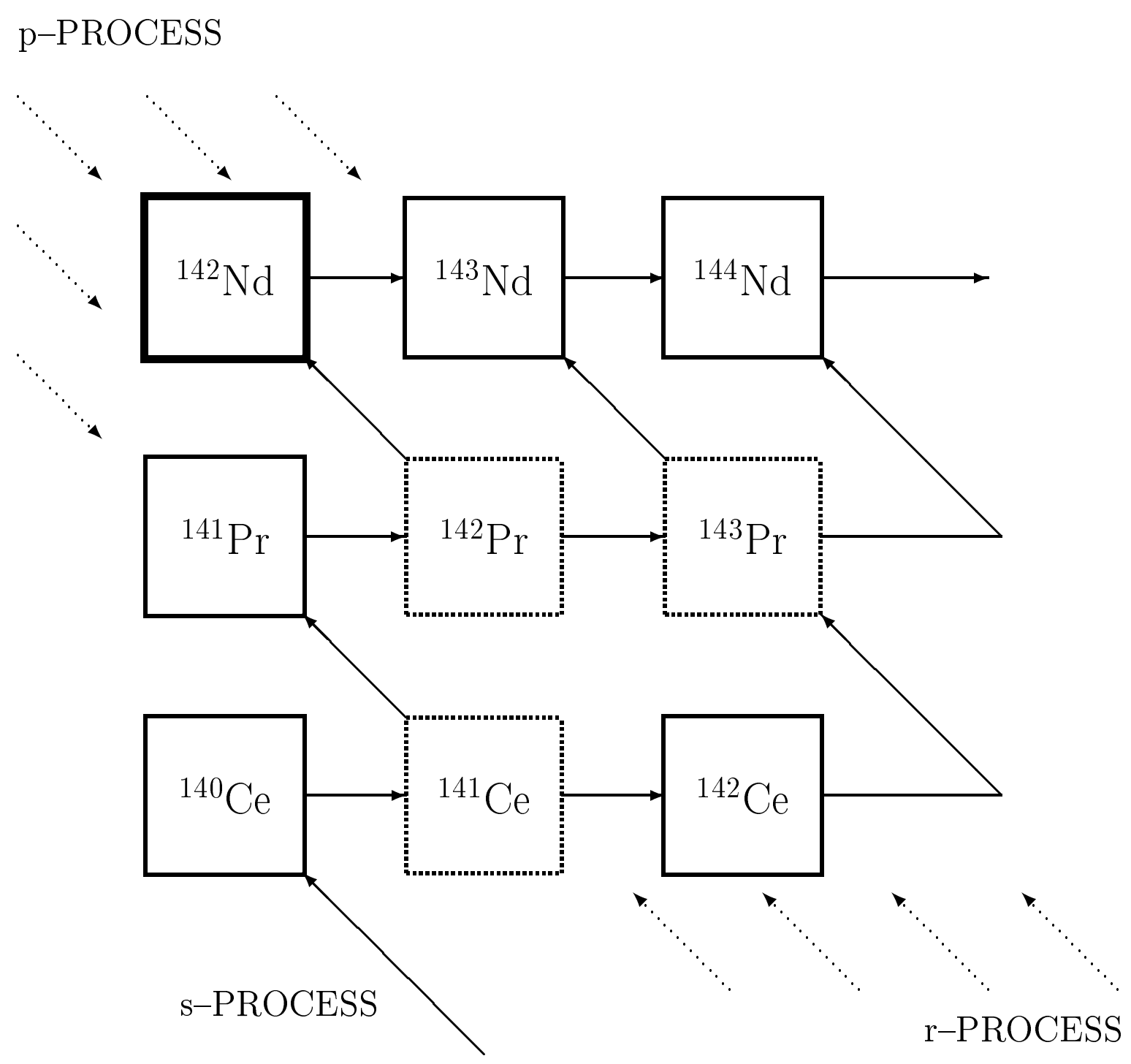




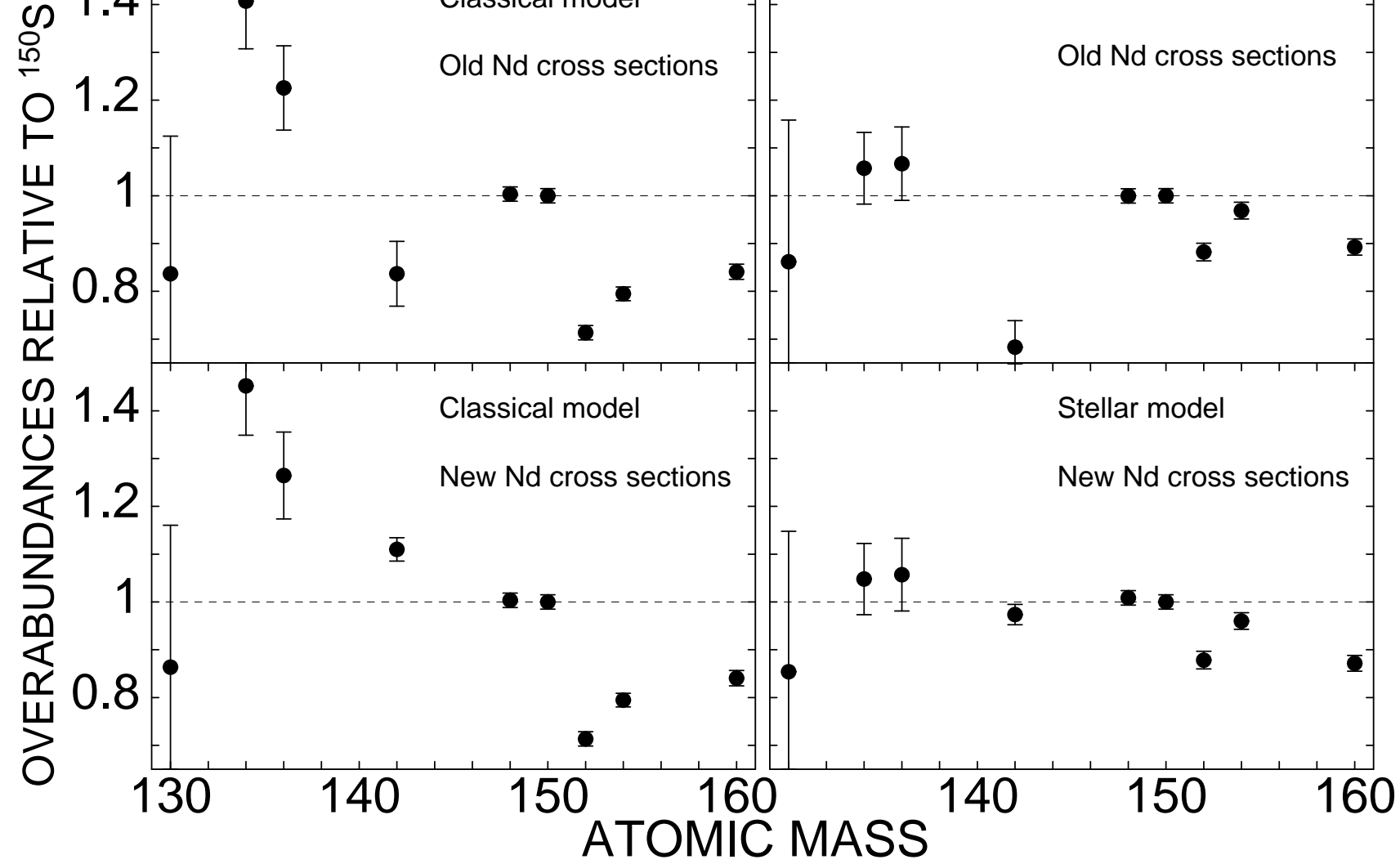




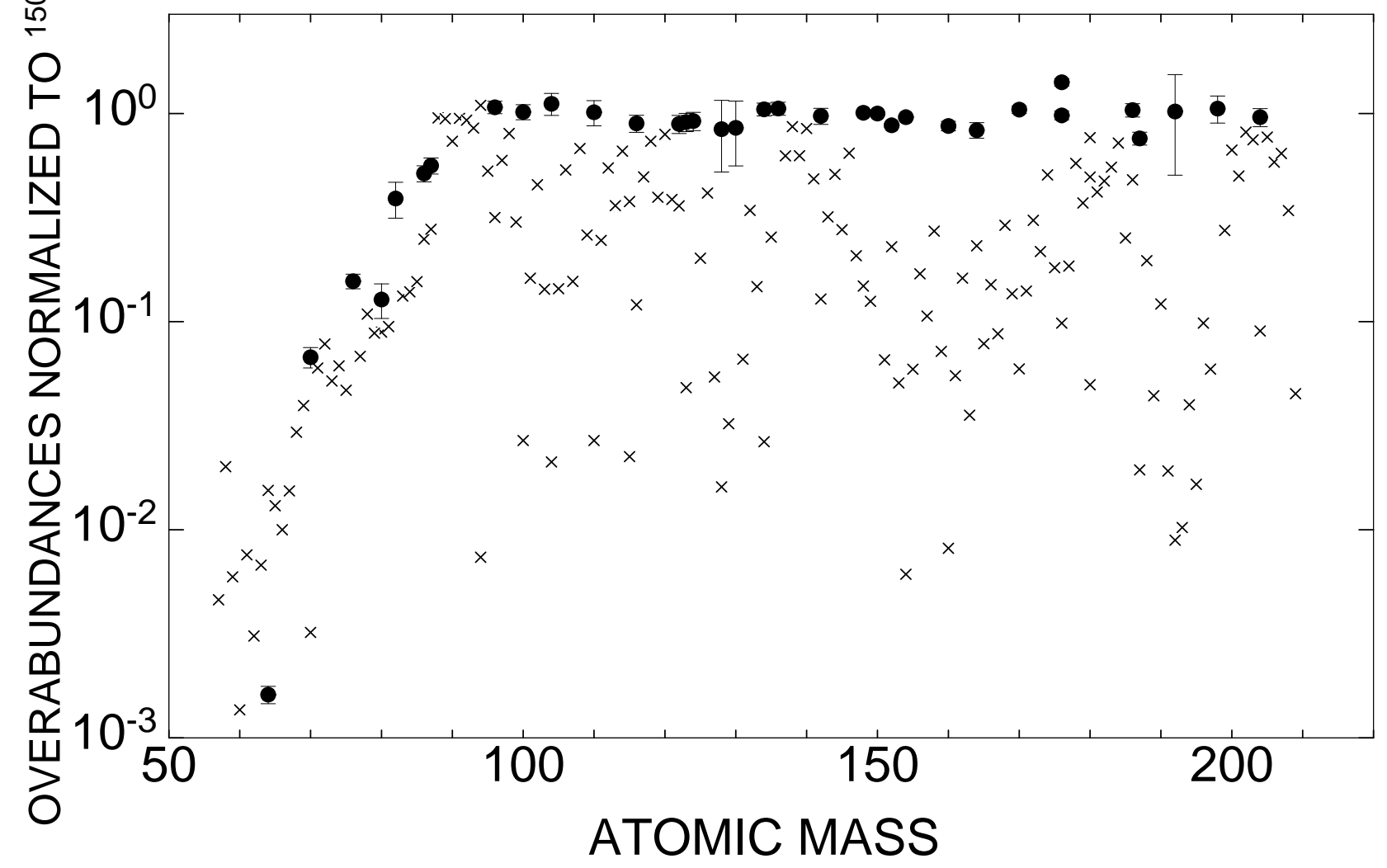




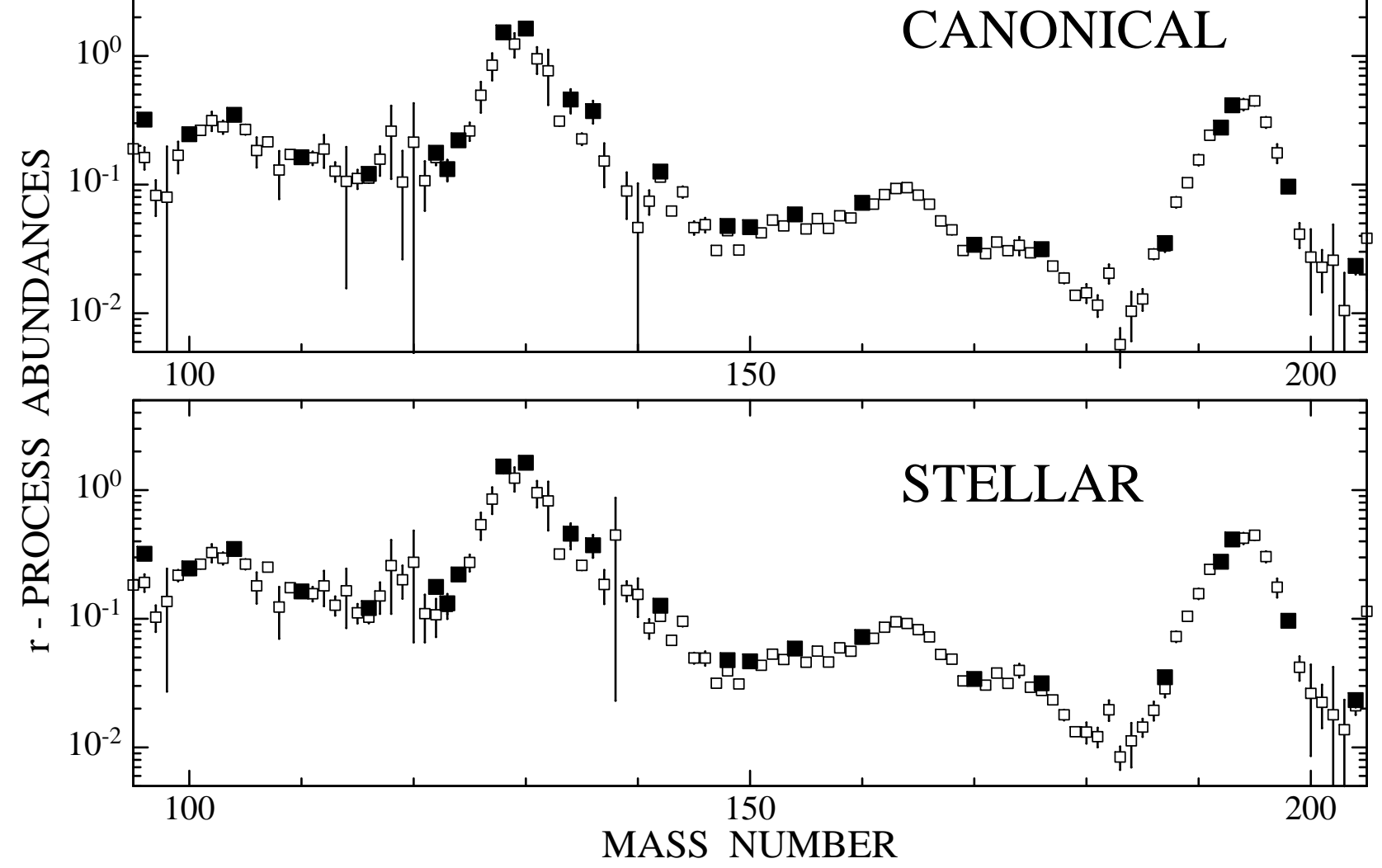

